\title{
Applications of the Horner-Wadsworth-Emmons Olefination in Modern Natural Product Synthesis
}

\author{
Dávid Roman $(D)$ \\ Maria Sauer \\ Christine Beemelmanns* (D) \\ Chemical Biology of Microbe-Host Interactions, Leibniz Institute for \\ Natural Product Research and Infection Biology - Hans-Knöll-Institute \\ (HKI), Beutenbergstrasse 11a, 07745 Jena, Germany \\ christine.beemelmanns@leibniz-hki.de
}

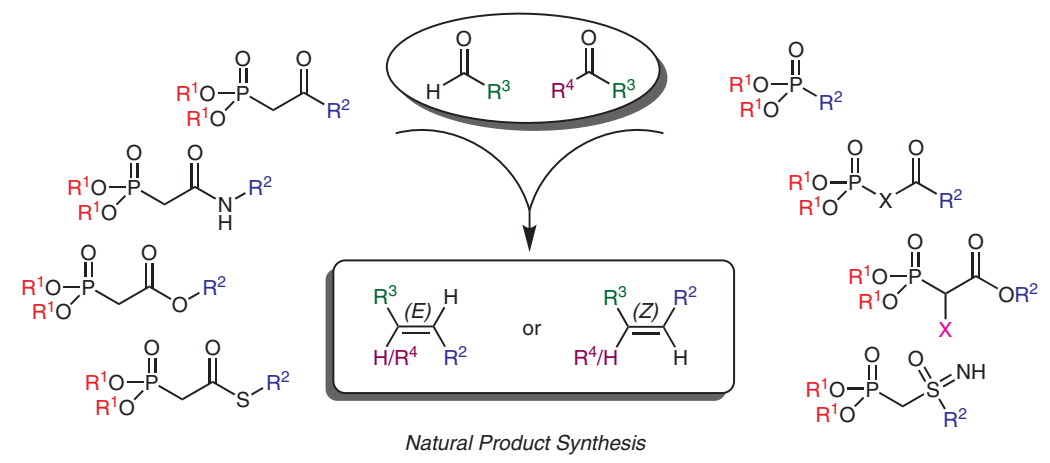

Received: 20.01.2021

Accepted after revision: 28.04.2021

Published online: 28.04 .2021

DOI: 10.1055/a-1493-6331; Art ID: ss-2021-z0027-r

License terms: (c)

(c) 2021. The Author(s). This is an open access article published by Thieme under the terms of the Creative Commons Attribution-NonDerivative-NonCommercial-License, permitting copying and reproduction so long as the original work is given appropriate credit. Contents may not be used for commercial purposes or adapted, remixed, transformed or built upon. (https://creativecommons.org/licenses/by-nc-nd/4.0/)

Abstract The Horner-Wadsworth-Emmons (HWE) reaction is one of the most reliable olefination reaction and can be broadly applied in organic chemistry and natural product synthesis with excellent selectivity. Within the last few years HWE reaction conditions have been optimized and new reagents developed to overcome challenges in the total syntheses of natural products. This review highlights the application of HWE olefinations in total syntheses of structurally different natural products covering 2015 to 2020. Applied HWE reagents and reactions conditions are highlighted to support future synthetic approaches and serve as guideline to find the best HWE conditions for the most complicated natural products.

Introduction and Historical Background

Applications of HWE

2.1 Cyclization by HWE Reactions

2.2.1 Formation of Medium- to Larger-Sized Rings

2.2.2 Formation of Small- to Medium-Sized Rings

2.3 Synthesis of $\alpha, \beta$-Unsaturated Carbonyl Groups

2.4 Synthesis of Substituted C=C Bonds

2.5 Late-Stage Modifications by HWE Reactions

2.6 HWE Reactions on Solid Supports

2.7 Synthesis of Poly-Conjugated C $=$ C Bonds

2.8 HWE-Mediated Coupling of Larger Building Blocks

2.9 Miscellaneous

3 Summary and Outlook

Key words HWE reaction, olefination, $\mathrm{C}=\mathrm{C}$ bond formation, phosphonate, aldehyde, alkenes, natural products

\section{Introduction and Historical Background}

Carbon-carbon double bonds are ubiquitous in natural and biologically active products and common motifs in organic building blocks. The formation of a $\mathrm{C}=\mathrm{C}$ bond, often referred to as olefination, is a fundamental reaction in organic chemistry and allows further transformations, such as oxidation, metathesis, or polymerization. The challenge of selectively introducing double bond motifs into polyfunctional molecules motivated organic chemists early on, and gained an enormous momentum when Wittig published his discovery on carbonyl olefination in 1954 (Figure 1 ), later called the Wittig reaction. He treated carbonyl compounds with substituted quaternary phosphonium salts in the presence of certain condensing agents and discovered that the intermediate phosphonium ylides reacted with the carbonyl compound to form an unstable intermediate, which then broke down to phosphine oxide and an olefin. ${ }^{1}$ This epochal discovery significantly changed the direction of olefination chemistry. Since then, the Wittig principle of double bond formation has been thoroughly studied and because of its effectiveness and applicability has led to the development of related transformations. ${ }^{2}$ Most notably, in 1958 Horner showed that the acidity of a phosphonate correlates with its reactivity to form a stabilized phosphonate carbanion that reacts with carbonyl compounds to yield an olefin. ${ }^{3}$ To prove his theory, he reacted methyldiphenylphosphine oxide with benzophenone in the presence of sodium amide in benzene and obtained the predicted products diphenylphosphinic acid and 1,1-diphenylpropene. Wadsworth and Emmons discussed the reaction reported by Horner and defined its limitations in $1961 .{ }^{4}$ They found that both the Wittig and Horner reactions share same principles but with the major difference that phosphonate carbanions are stabilized by electronwithdrawing groups, which makes them more nucleophilic and less basic compared to phosphonium ylides (Figure 2). The systematic exploration of the now titled HornerWadsworth-Emmons (HWE) olefination opened a wide range of new possibilities and quickly became one of the most intensively studied and commonly applied reactions for selective double bond formation. 


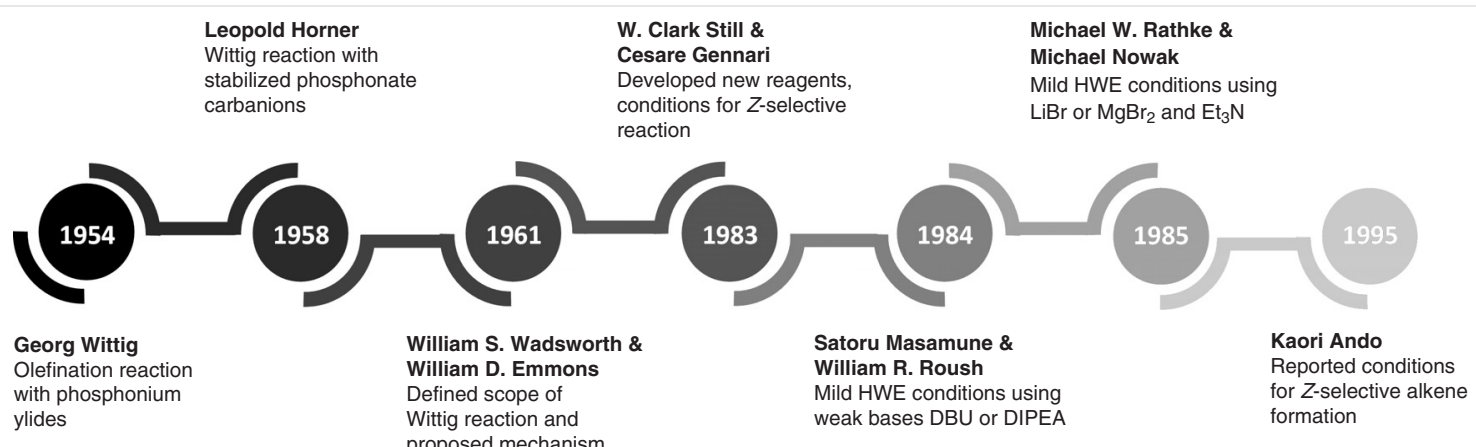

Figure 1 Historical timeline capturing the most important discovery milestones in the development of the Horner-Wadsworth-Emmons reaction

In 1983 Still and Gennari modified the HWE reaction to obtain almost exclusively $Z$-selective alkenes. ${ }^{5,6}$ This transformation was achieved by using electrophilic bis(trifluoroethyl)phosphonoacetate in combination with a strong dis- sociating base, such as potassium hexamethyldisilazanide (KHMDS) and 18-crown-6 in THF, which allowed highly stereoselective formation of $Z$-unsaturated esters. In 1995, Ando reported that the use of ethyl diphenylphosphono-

\section{Biographical Sketches

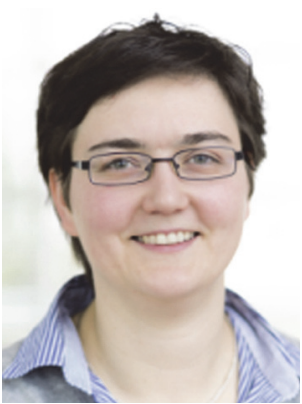 \\ Christine Beemelmanns (1981) received her diploma in chemistry at the RWTH Aachen (Germany) in 2006. After a one- year research stay in Prof. Mikiko Sodeoka's group at RIKEN (Wako-Shi, Japan) she then per- formed her Ph.D. under the su- pervision of Prof. Hans-Ulrich \\ dustrie and the Studienstiftung des Deutschen Volkes. After postdoctoral stays in Prof. Keis- uke Suzuki's group at the Tokyo Institute of Technology (Tokyo, Japan) and Prof. Jon Clardy's group at Harvard Medical School (USA), supported by fel- lowships from the German Ex- \\ Leopoldina, she joined the Leib- niz Institute for Natural Product Research and Infection Biology (Jena, Germany) as junior re- search group leader at the end of 2013. Her research focuses on the isolation, characteriza- tion, and total synthesis of mi- crobial signaling molecules.}

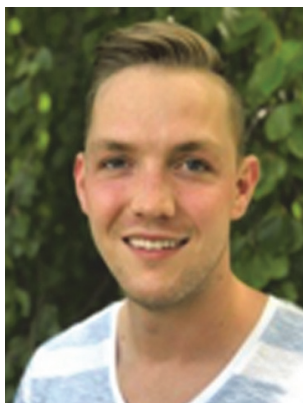
Reissig with a fellowship from the Fonds der Chemischen In-

Dávid Roman received his B.Sc. degree in chemistry (2015) and M.Sc. degree in organic chemistry (2017) from University of Pavol Jozef Šafárik in Košice (Slovakia). After his graduation in 2017, he joined the lab of Dr Andreas Lerchner

Maria Sauer received her B.Sc. and M.Sc. degrees in chemistry (2019) from Friedrich-SchillerUniversity in Jena (Germany). In change Service and German National Academy of Sciences

in the DAx Global Discovery Chemistry (GDC) department of Novartis Institute for Biomedical research (NIBR) in Basel (Switzerland) for a research stay. Since 2018, he has been performing his doctoral studies in the group of Chemical Biology

of Microbe-Host Interactions led by $\mathrm{Dr}$ Christine Beemelmanns at the Hans-Knoll Institute in Jena (Germany). His main research focuses on total synthesis and derivatization of natural products of microbial origin.

2019, she joined Dr. Christine Beemelmanns' group where she is currently working on method development and applications in total synthesis of biologically active natural products as part of her doctoral studies. 


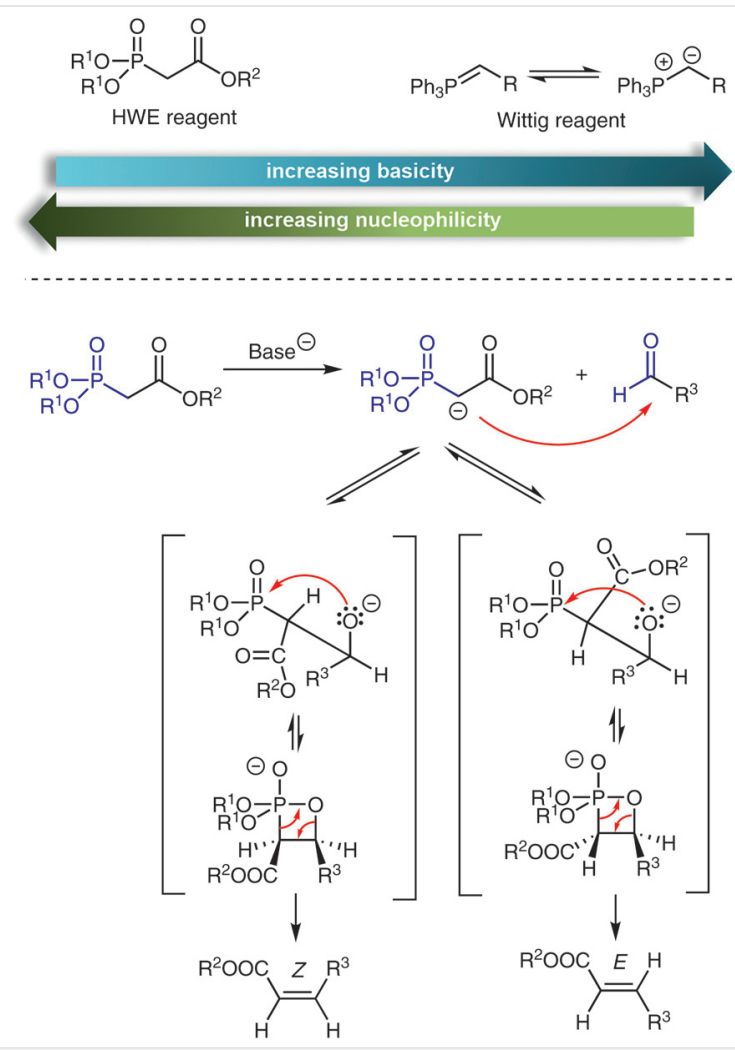

Figure 2 Reaction mechanism of the HWE reaction

acetate results in an almost exclusive formation of $Z$ alkenes by using Still's conditions [KHMDS/18-crown-6] and benzyltrimethylammonium hydroxide (Triton B) as a base. $^{7}$

Shortly after the reports by Still and Gennari, Masamune and Roush reported in 1984 that the presence of lithium chloride leads to complexation of the phosphonate reagent, which results in increased acidity and reactivity; weaker bases like DBU or diisopropylethylamine (DIPEA) can be used for deprotonation. ${ }^{8}$ Rathke and Nowak extended these studies in 1985 and reported that the use of $\mathrm{LiBr}$ or $\mathrm{MgBr}_{2}$ and triethylamine leads to a conversion of aldehydes and ketones with similar yields to those reactions reported with strong bases. ${ }^{9}$ These studies triggered a cascade of explorations to optimize the conditions for HWE reactions (phase transfer catalyst, ${ }^{10}$ microwave irradiation, metal-promoted HWEs), ${ }^{11}$ selectivity (enantioselective or diastereoselective transformations), ${ }^{12}$ and substrate scope. While these seminal findings unraveled the correlation of acidity, complexation, and reactivity in phosphonate-based olefination reactions, they also stimulated the usage of other heteroatom- stabilized carbanions. This mainly includes the JuliaKocienski olefination (methylated aryl alkyl sulfones) ${ }^{13}$ and Peterson olefination ( $\alpha$-silyl carbanion). ${ }^{14}$

The enormous numbers of HWE reaction possibilities in addition to its functional group compatibility and selectivity resulted in its wide synthetic use, in particular in natural product synthesis. Building up on preceding reviews that discuss the mechanisms and reaction scopes of Wittig ${ }^{2}$ and HWE reactions,$^{15}$ this review aims to highlight the diversity of employed HWE reagents and their applications in natural product total syntheses covering 2015 to 2020 (Scheme 1). Subsections are structured chronologically and according to the formation of macrocycles, such as small to medium rings, $\alpha, \beta$-unsaturated carbonyls, and conjugated double bonds. The applied reagents and reaction conditions of the herein described syntheses are highlighted in Table 1 and allow the reader to navigate through the diversity of HWE reactions and support identifying suitable reagents and conditions for challenging natural product syntheses.

\section{Applications of HWE}

\subsection{Cyclization by HWE Reactions}

At the being of the 1970s the HWE reaction was examined a synthetic tool in the synthesis of lactones, ${ }^{39}$ lactams, ${ }^{40}$ macrocycles, ${ }^{41}$ and hetero-polycycles. ${ }^{42}$ Since then, intramolecular HWE-based cyclization reactions have become very popular in natural product total synthesis due to their functional group tolerance, high yields, and selectivity. ${ }^{43}$

\subsubsection{Formation of Medium- to Larger-Sized Rings}

Polyfunctionalized macrocyclic natural products are ubiquitous in nature. Their stereochemical complexity and ring size most often confers high bioactivities, thus making them interesting targets for medicinal and organic chemists. ${ }^{44}$ To showcase the application of HWE reaction, we selected four recent literature examples.

Cytochalasans are a diverse group of polyketide-derived macrocycles of fungal origin, which are known for their broad range of biological activities. ${ }^{45}$ This includes cytotoxic, immunomodulatory, and nematicidal properties. ${ }^{46}$ The cytochalasan family has been a popular synthetic target for decades ${ }^{47}$ and numerous reports describe synthetic strategies towards cytochalasin $\mathrm{B},{ }^{48}$ cytochalasin $\mathrm{H}^{49}$ cytochala$\sin O,^{50}$ chaetochalasin $A,{ }^{51}$ aspochalasin $B,{ }^{52}$ and other related congeners of the cytochalasan family. 
A)

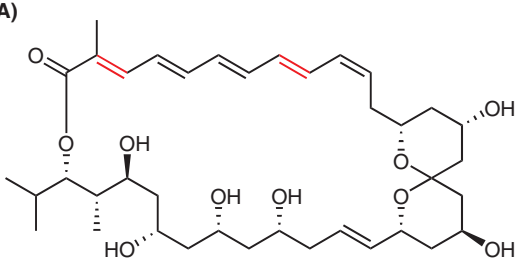

1

(-)-marinisporolide C Dias and de Lucca (2017) ${ }^{63}$

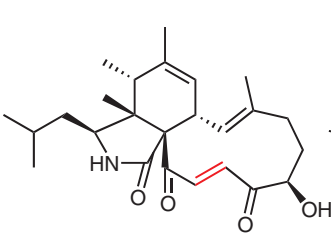

2

(-)-aspochalasin B Trauner and co-workers $(2018)^{53}$ Deng and co-workers (2018) ${ }^{34}$

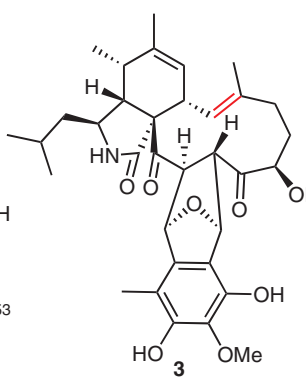

asperchalasine $D$ Deng and co-workers (2018) ${ }^{34}$<smiles>C=C/C=C/Cc1ccco1</smiles>

(-)-lasonolide A Hong and co-workers (2018) $)^{33}$

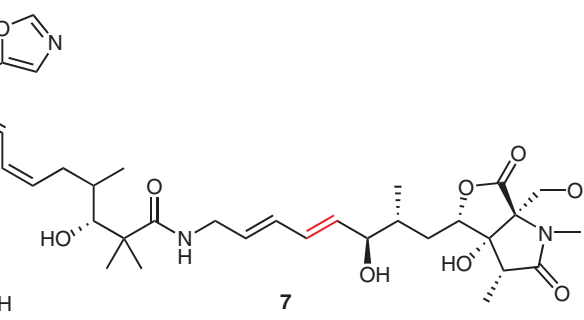

(+)-neooxazolomycin Kim and co-workers (2019) ${ }^{25}$

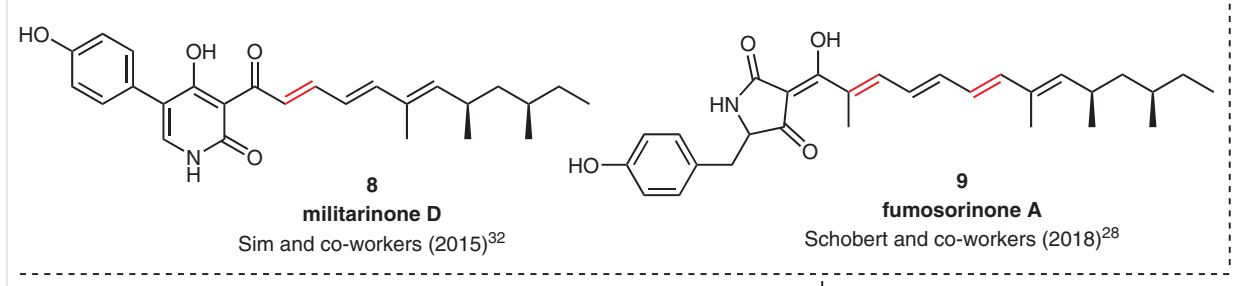

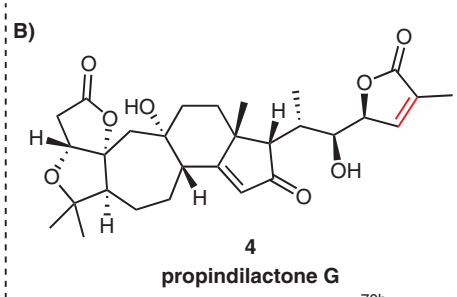

Gui and co-workers (2020) ${ }^{70 b}$

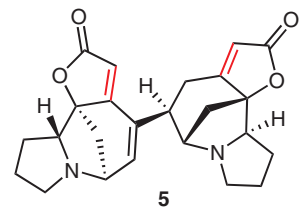

(-)-flueggenine C Han and Jeon (2017) 70a

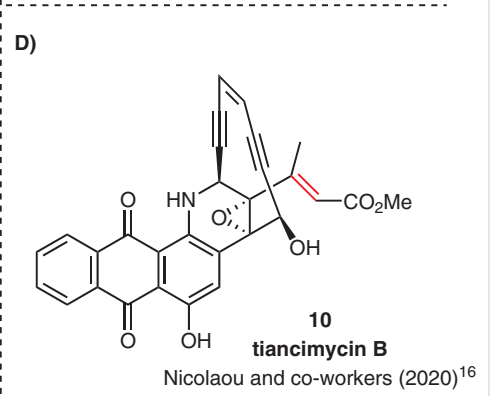

E)

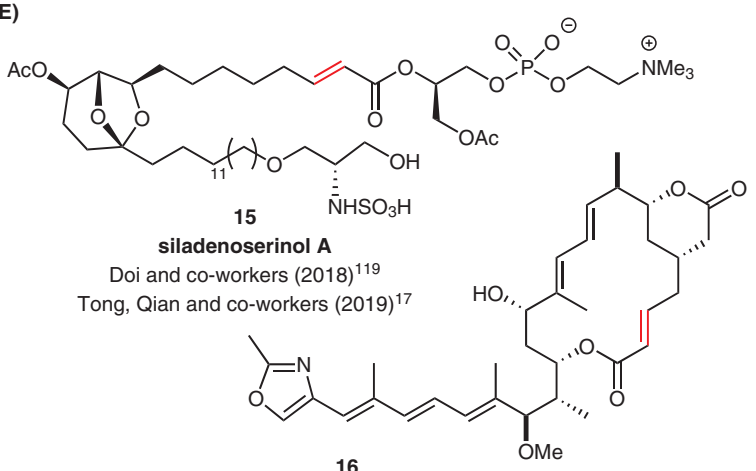

rhizoxin D

Fürstner and co-workers (2019) ${ }^{123}$

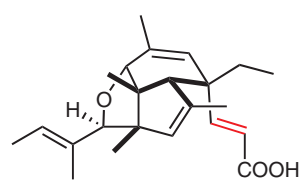

11

(-)-indoxamycin A Liang and co-workers $(2019)^{85}$

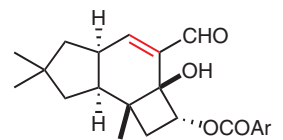

13

melleolide

Takasu and co-workers (2019) ${ }^{18}$<smiles>C/C=C(\C)[C@H]1O[C@H](C2C[C@H](CC(C)C)NC2=O)C[C@@H]2CC=C(C)C[C@@H]21</smiles>

Lindsley and co-workers (2019) ${ }^{80}$<smiles>CCCCCc1cccc(OC)c1C(=O)C[C@@H](C(=O)O[C@@H](C)C(=O)NC/C=C(\Cl)C(=O)OC)[C@@H](C)CC</smiles>

14

anaenamide $A$

Luesch and co-workers (2020) ${ }^{31}$
Scheme 1 Examples of some natural products synthesized using HWE reactions (highlighted red) presented herein incorporated in their total syntheses. Natural products are sorted according the outcome of the HWE reaction within their synthetic strategy for the formation of (A) macro- and medium-sized $\alpha, \beta$-unsaturated rings, (B) small rings, (C) polyconjugated $C=C$ bonds, (D) $\alpha, \beta$-unsaturated esters and enones, and (E) coupling of larger building blocks. 
2717

THEME

Synthesis

D. Roman et al.

OPEN
ACCESS

Review

Table 1 Summary of Some HWE Reagents and Conditions Sorted According to the General Formulas Presented

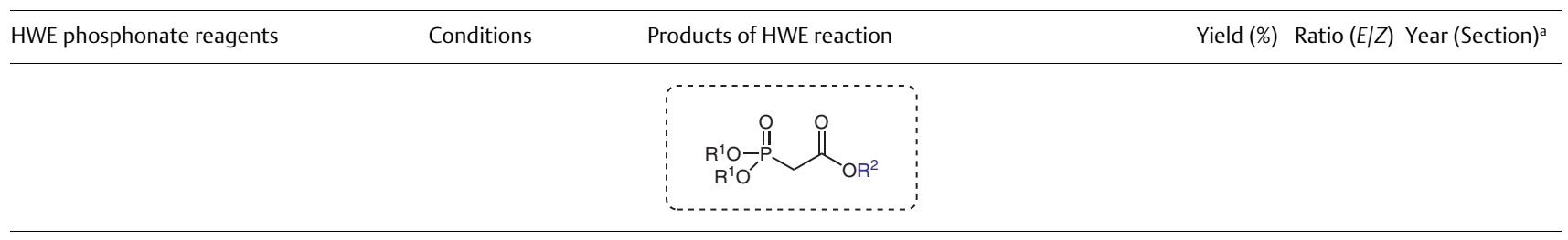

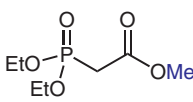

17

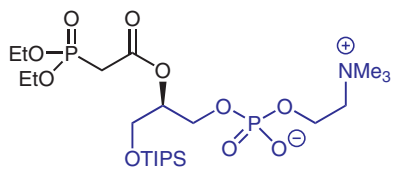

18

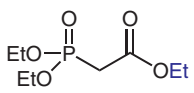

20

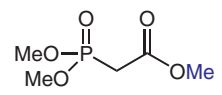

22
$\mathrm{NaH}, \mathrm{THF}$

-78 to $0{ }^{\circ} \mathrm{C}$, ca $5 \mathrm{~h}$

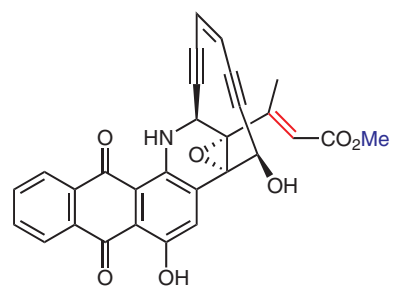

10

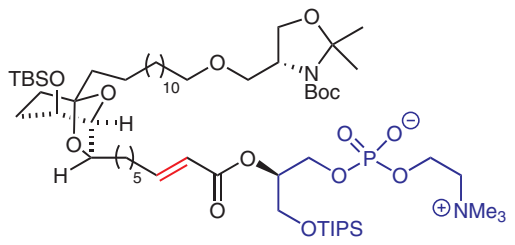

19
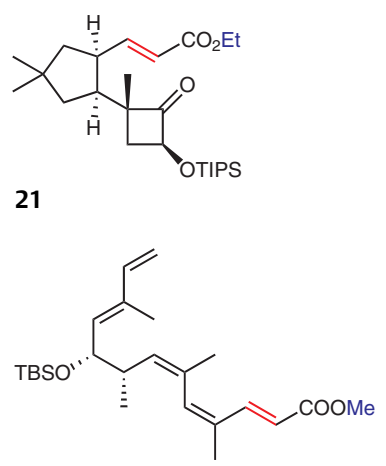
$0{ }^{\circ} \mathrm{C}, 4.5 \mathrm{~h}$
84

$8: 1$

$2020^{16}$

(2.5)

$77 \quad$ only $E \quad 2019^{17}$

(2.8)
21

23

$\mathrm{NaH}$, toluene $0{ }^{\circ} \mathrm{C}$ to rit., $1.5 \mathrm{~h}$

n-BuLi, DMPU, THF

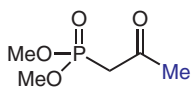

$\mathrm{NaH}, t$-BuSK, THF $-78{ }^{\circ} \mathrm{C}$ to ret., ca. $1 \mathrm{~h}$

24

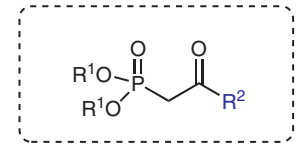

98

20:1

$2019^{19}$ $(-\mathrm{b})$<smiles>CC(=O)/C=C1\CCCN([C@H]2C=CC3=CC(=O)O[C@@H]3C2)C1=O</smiles>

25

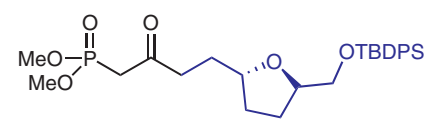

26
LiCl, DIPEA, MeCN $0{ }^{\circ} \mathrm{C}$ to rit., $8 \mathrm{~h}$

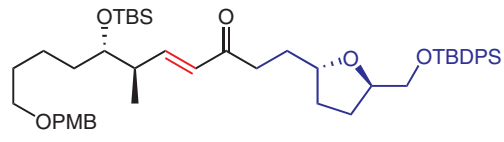

27

$\begin{array}{ll}20(2 & \\ \text { steps }) & \text { only } E\end{array} \quad \begin{aligned} & 2020^{20} \\ & \left(-^{\mathrm{b}}\right)\end{aligned}$

91

only $E$

$2020^{21}$
$(2.8)$

Synthesis 2021, 53, 2713-2739 
Table 1 (continued)

HWE phosphonate reagents

Conditions

Products of HWE reaction

Yield (\%) Ratio (E/Z) Year (Section) ${ }^{\mathrm{a}}$<smiles>CCOP(=O)(CC(=O)[C@@H](C)[C@H](O[SbH3])[C@H]1C[C@@H](C)[C@@H](CCOCc2ccccc2)O1)OCC</smiles>

28

$\mathrm{Ba}(\mathrm{OH})_{2} \cdot 8 \mathrm{H}_{2} \mathrm{O}, \mathrm{THF}$ r.t., $1 \mathrm{~h}$

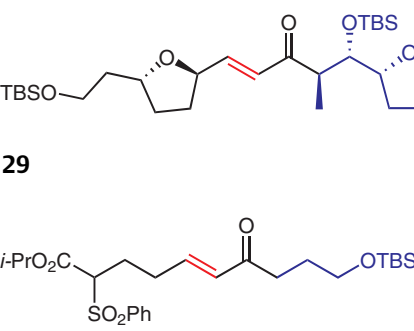<smiles>COP(=O)(CC(=O)CO[SbH3])OC</smiles>

32

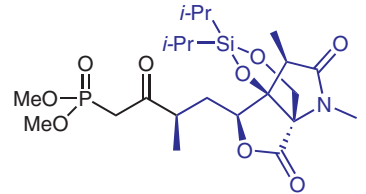

34
31

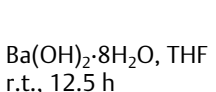
r.t., $12.5 \mathrm{~h}$

$\mathrm{LiCl}, \mathrm{Et}_{3} \mathrm{~N}, \mathrm{THF}$ 0 to $40{ }^{\circ} \mathrm{C}, 2.5 \mathrm{~h}$<smiles>CC(C)C(/C=C/C(=O)C[Se-])C[OH2+]</smiles>

33

$\mathrm{Ba}(\mathrm{OH})_{2}, \mathrm{THF} / \mathrm{H}_{2} \mathrm{O}$ $-30{ }^{\circ} \mathrm{C}, 16 \mathrm{~h}$

35

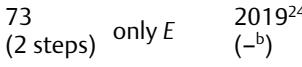

75

only $E$<smiles>CCOP(=O)(C/C=C(\C)C(=O)OC)OCC</smiles>

36<smiles>CCOP(=O)(C/C=C(\C)C(=O)OC)OCC</smiles>

36<smiles>CCOC(=O)/C=C/CP(=O)(OCC)OCC</smiles>

39<smiles>CCOC(=O)/C=C/C=C/CP(=O)(OC)OC</smiles>

41<smiles>CCOC(=O)C=C(C)C(C)P(=O)(OCC)OCC</smiles>

43
LiHMDS, HMPA, THF $-78{ }^{\circ} \mathrm{C}$ to r.t., $2 \mathrm{~h}$<smiles>CCC(C)C=CC=C(C)C=CC=C(C)C(=O)OC</smiles>

37

n-BuLi, THF $-78{ }^{\circ} \mathrm{C}$ to r.t., ca $1 \mathrm{~h}$<smiles>COC(=O)/C(C)=C/C=C/[C@H](C)[C@H](O[Sb])c1ccccc1</smiles>

38

$\mathrm{NaH}, \mathrm{THF}$ $0{ }^{\circ} \mathrm{C}$ to r.t.

LDA, THF -78 to $0^{\circ} \mathrm{C}, 2 \mathrm{~h}$

n-BuLi, THF r.t., $17 \mathrm{~h}$<smiles>CCOC(=O)/C=C/C=C/C(C)=C/[C@H](C)C[C@@H](C)CC</smiles>

40<smiles>C=CC1OC(/C=C/C=C/C=C/C(=O)OCC)C(O)C(C)(C)O1</smiles>

42<smiles>CCOC(=O)/C=C(C)/C(C)=C/CC[C@H]1O[C@H](CNC(C)=O)[C@@H]([18OH])C[C@H]1C</smiles>

44
$69 \quad$ only $E \quad \begin{aligned} & 2019^{26} \\ & \left(-^{\mathrm{b}}\right)\end{aligned}$

$96 \quad 5.6: 1 \quad \begin{array}{ll}2017^{27} \\ \left(-^{\mathrm{b}}\right)\end{array}$

$\begin{array}{lll}67 & 95 \% \text { de } & 2018^{28} \\ & (2.7)\end{array}$

$\begin{array}{lll}60 & 2017^{29} \\ \text { (2 steps) } & 5: 1 & (2.7)\end{array}$

62 only 
2719

THIEME

Synthesis

D. Roman et al.

Review

Table 1 (continued)

\begin{tabular}{llll}
\hline HWE phosphonate reagents & Conditions & Products of HWE reaction & Yield (\%) Ratio (E/Z) Year (Section) \\
\hline & & & \\
& & &
\end{tabular}

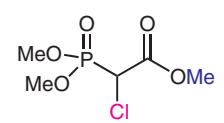

45

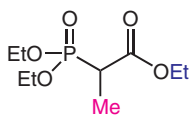

47

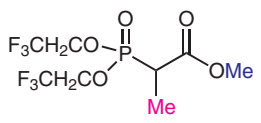

49

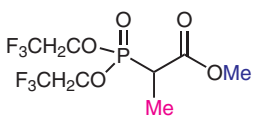

49

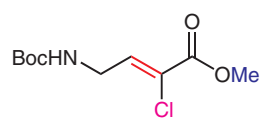

46

$\mathrm{NaH}, \mathrm{THF}$ $0{ }^{\circ} \mathrm{C}$ to r.t., $1 \mathrm{~h}$

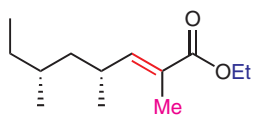

48

18-crown-6, KHMDS, THF $-78^{\circ} \mathrm{C}, 2 \mathrm{~h}$

18-crown-6, KHMDS, $\mathrm{THF}-78{ }^{\circ} \mathrm{C}, 1.5 \mathrm{~h}$

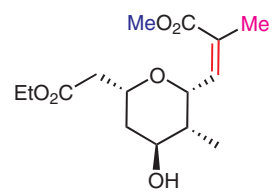

50

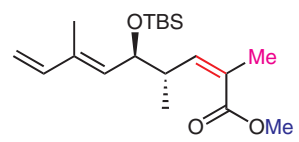

51 $\begin{array}{lll}50 & 6: 1 & 2020^{31} \\ & & (2.4)\end{array}$

$\begin{array}{ll}71 & 1.2: 3 \\ \text { (2 steps) }\end{array}$

$2015^{32}$

(2.7)

$74\left(2\right.$ only $Z \quad 2018^{33}$

(2.7)

90

$1: 20$

$2019^{19}$ $\left(-^{\mathrm{b}}\right)$

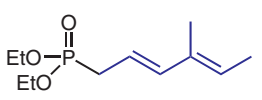

52

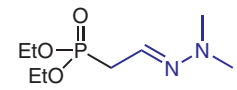

54

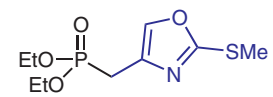

56
KHMDS, THF $0{ }^{\circ} \mathrm{C}, 10 \mathrm{~min}$

LDA, THF r.t., $12 \mathrm{~h}$

n-BuLi, THF -78 to $0{ }^{\circ} \mathrm{C}, 1.5 \mathrm{~h}$
82

$7: 1$

$2018^{34}$

(2.2.1)

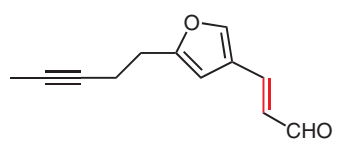

86 only $E$

$2016^{23}$

55

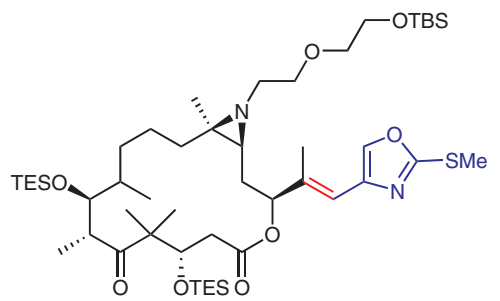

57

Synthesis 2021, 53, 2713-2739 


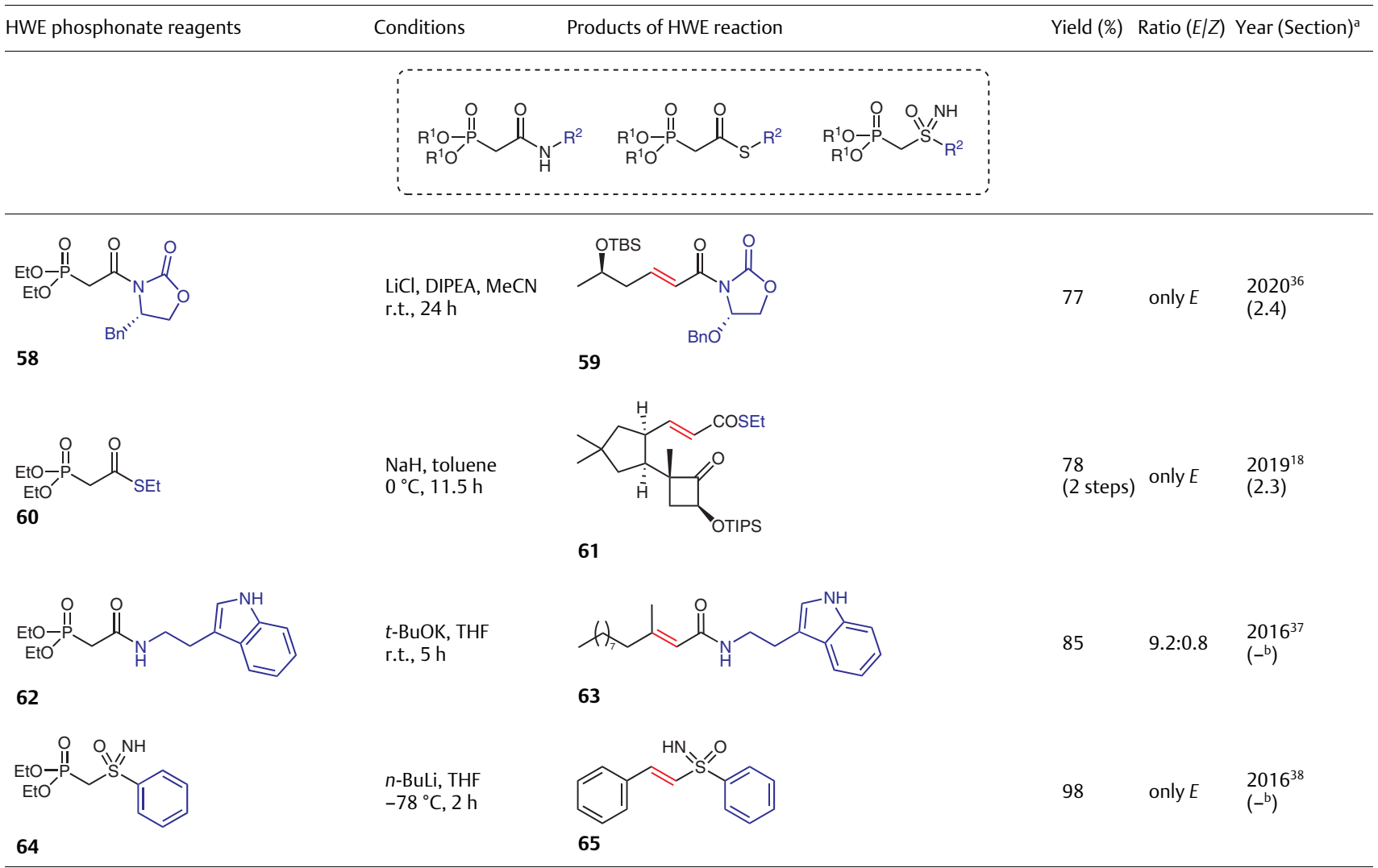

a Section in which relevant material can be found for this synthesis.

${ }^{\mathrm{b}}$ Not discussed in following sections.

An excellent example of a ring-closing HWE reaction in the total synthesis of (-)-aspochalasin $\mathrm{D}(\mathbf{7 2})$ was described in 2018 by Trauner and co-workers (Scheme 2). ${ }^{53}$ Their strategy started with epoxy alcohol $\mathbf{6 6}$ that was converted into isoindolone moiety $\mathbf{6 7}$ in 7 steps. Addition of dimethyl lithiomethylphosphonate (68) yielded $N$-debenzoylated phosphonate 69. Aldehyde $\mathbf{7 0}$ was formed following selective TBS deprotection and oxidation with the Dess-Martin periodinane (DMP) of the primary alcohol. The HWE reaction using Masamune and Roush conditions ( $\mathrm{LiCl}$, DIPEA, $\mathrm{MeCN}$ ) afforded macrocycle $\mathbf{7 1}$ without epimerization in 3 steps and $46 \%$ yield. ${ }^{8}$ The synthesis of (-)-aspochalasin D (72) was completed by TBS deprotection using tetrabutylammonium fluoride, while acidic TBS deprotection using HF in acetonitrile yielded aspergillin PZ (73) in 89\% yield. (-)-Aspochalasin D (72) was treated in $45 \%$ yield.

Deng and co-workers accomplished the first total syntheses of asperchalasines A, D, E, and H in 2018, which included a highly diastereoselective intermolecular DielsAlder reaction and an HWE macrocyclization step to yield the monomer aspochalasin B (2) (Scheme 3). ${ }^{34}$ Their synthesis started with the stereospecific synthesis of triene fragment 53, starting from L-arabinose via a known 3-step sequence to obtain hemiacetal $\mathbf{7 4} .^{54}$ This was followed by a Wittig reaction, TBS-protection, and the hydrogenation of the double bond to yield methyl ketone $\mathbf{7 5}$ in 69\%. Methyl ketone $\mathbf{7 5}$ was directly subjected to an HWE reaction with dienyl phosphonate $\mathbf{5 2}$ under strongly basic conditions to give the conjugated triene 53 in $82 \%$ yield $(E / Z \sim 7: 1) .{ }^{55}$ The synthesis of lactam 77 was achieved in 8 steps from $N$-BocL-leucine 76 via $C$-acylation with methyl chloroformate, ${ }^{56}$ selenylation, and oxidative elimination. Heating a mixture of 53 and $77\left(100{ }^{\circ} \mathrm{C}\right.$, neat) resulted in the formation of the Diels-Alder product 78 (E/Z 2:1). The phosphonate was installed by addition of dimethyl lithiomethylphosphonate to the methyl ester 78. Deprotection and oxidation of the primary alcohol yielded aldehyde $\mathbf{7 9}$ as a substrate for HWE macrocyclization. The 11-membered enone $\mathbf{7 2}$ was not achieved after screening different reaction conditions (KHMDS, $\mathrm{NaH}, \mathrm{LiBr} / \mathrm{Et}_{3} \mathrm{~N}^{9} \mathrm{~K}_{2} \mathrm{CO}_{3} / 18$-crown- $66^{57}$ or $\mathrm{NaOCH}_{2} \mathrm{CF}_{3}{ }^{58}$ ). Only a mild Lewis acid, $\mathrm{Zn}(\mathrm{OTf})_{2}$, in combination with TMEDA and triethylamine was found to promote intramolecular HWE olefination. This was followed by TBS deprotection to obtain enone (-)-aspochalasin D (72) in $79 \%$ with minimal 


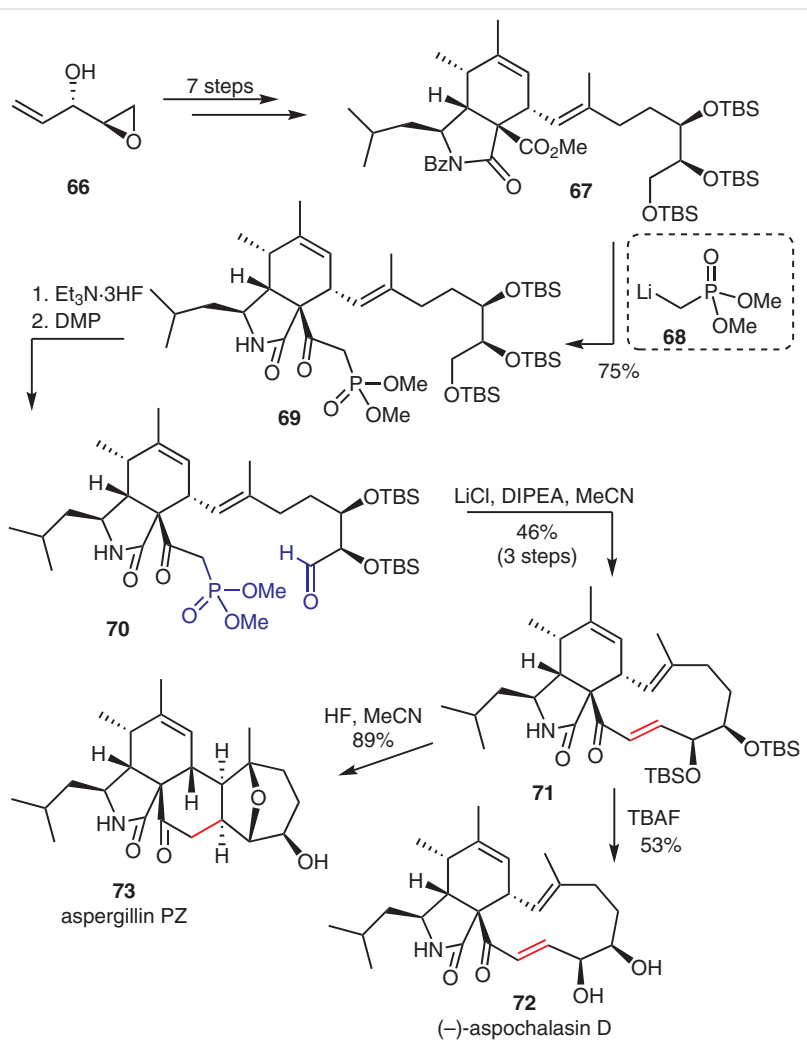

Scheme 2 Synthesis of (-)-aspochalasin D and aspergillin PZ by Trauner and co-workers

epimerization at $\mathrm{C} 18 .{ }^{59}$ The synthesis of (-)-aspochalasin B (2) was completed after oxidation of the allylic alcohol in (-)-aspochalasin D (72) with TEMPO in $92 \%$ yield.
Naturally occurring 12,14 , or 16 -membered macrolides are most often of polyketide origin and have been shown to exhibit diverse pharmacological activities. ${ }^{60} \mathrm{~A}$ series of new 14-membered macrolides, named pestalotioprolides $\mathrm{B}-\mathrm{H}$, were discovered from the mangrove-derived endophytic fungus Pestalotiopsis microspora by Liu, Proksch, and coworkers in 2016; the derivatives showed significant cytotoxicity against the murine lymphoma cell lines. ${ }^{61}$ The first total synthesis of derivatives pestalotioprolide $\mathrm{E}(\mathbf{8 3})$ and pestalotioprolide $F(\mathbf{8 4})$, with revision of its proposed structure, was accomplished by Goswami and co-workers (Scheme 4). ${ }^{62}$ The key step of this synthesis was the HWE reaction of $\mathbf{8 1 a}$ and $\mathbf{8 2 b}$, which were obtained by partial hydrogenation of Sonogashira products 80a and 80b. Oxidation of the primary alcohols yielded the corresponding aldehydes 81a and 81b that were necessary for the intramolecular HWE reaction.

After testing different macrocyclization conditions, the combination of $\mathrm{LiCl} / \mathrm{DIPEA}$ or $\mathrm{Ba}(\mathrm{OH})_{2} \cdot 8 \mathrm{H}_{2} \mathrm{O}$ were found to provide macrocycles $\mathbf{8 2 a}$ and $\mathbf{8 2 b}$ in optimized $30 \%$ yield. Subsequent desilylation of $\mathbf{8 2 a}$ and $\mathbf{8 2 b}$ resulted in pestalotioprolide $\mathrm{E}(\mathbf{8 3})$ and the revised structure of pestalotioprolide $\mathrm{F}(\mathbf{8 4})$, respectively.

Dias and de Lucca designed the first total synthesis of the 30-membered (-)-marinisporolide C (1) in 2017, which allowed the determination of the relative and absolute configuration of the natural product (Scheme 5). ${ }^{63}$ Aldehyde $\mathbf{8 5}$ was prepared in 16 steps and elongated using Takai-Utimoto olefination with $\mathrm{CHI}_{3}$ producing vinyl iodide 86 in $82 \%$ yield. ${ }^{64}$ The free $\mathrm{OH}$ group in $\mathbf{8 6}$ was then subjected to Yamaguchi esterification with $\mathbf{8 7}$ to afford $\mathbf{8 8}$ in $92 \% .{ }^{65}$ Treatment with HF.pyridine led to global TBS deprotection and spiroketal formation. The remaining hydroxyl groups

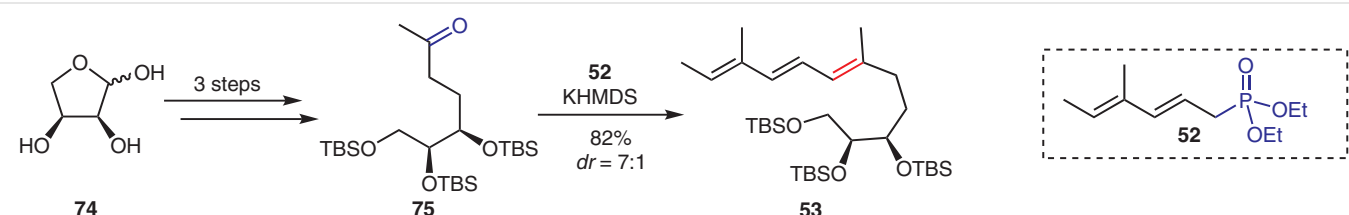

74

75

$\underset{\substack{85 \% \\ E / Z=2: 1}}{\stackrel{53}{\text { neat, } 100{ }^{\circ} \mathrm{C}}}$

77

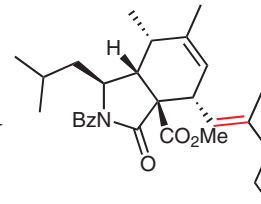

78
1. BuLi, MePO(OMe $)_{2}$ 2. HF.pyridine 3. DMAP<smiles>C=CC(=O)OC(=O)CC(C)C</smiles>

76

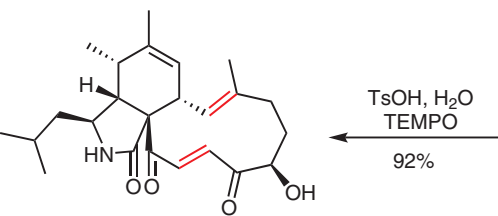
2 aspochalasin B

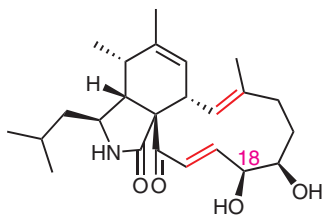

72 aspochalasin $D$

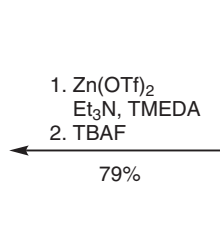

79

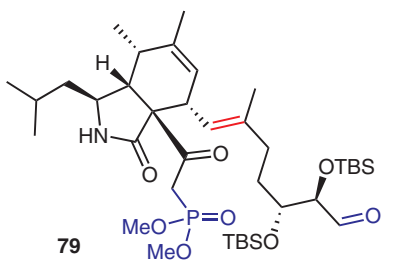

Scheme 3 Total synthesis of (-)-aspochalasin D and aspochalasin B by Deng and co-workers 

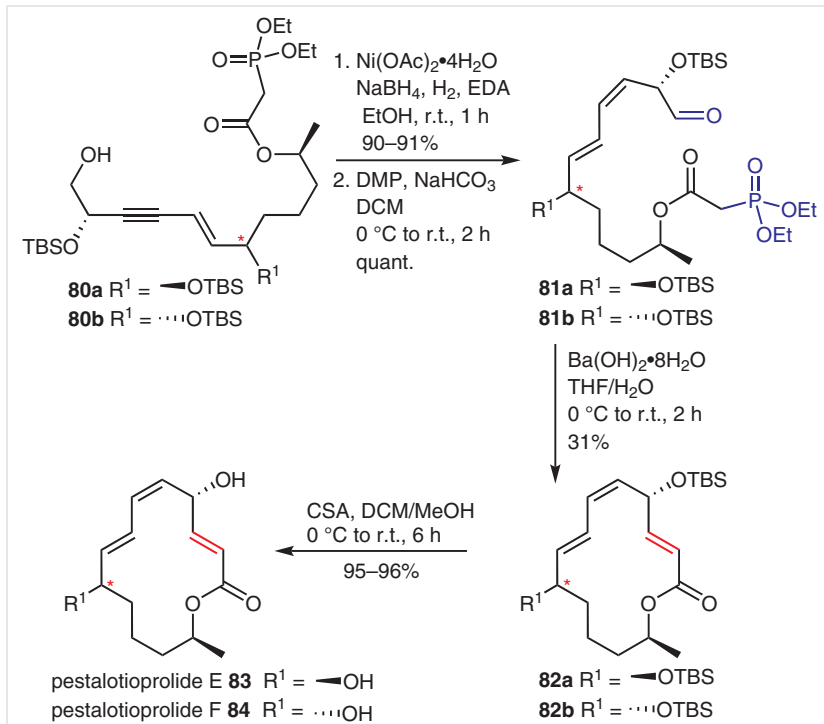

Scheme 4 Synthesis of pestalotioprolide E and pestalotioprolide F

were again protected with tert-butyldimethylsilyl trifluoromethanesulfonate (TBSOTf) and afforded spiroketal 89. Stille cross-coupling with $\mathbf{9 0}$ followed by oxidation of the primary alcohol with TEMPO and bis(acetoxy)iodobenzene (BAIB) provided the necessary aldehyde 91. HWE olefination to the macrocycle was accomplished using MasamuneRoush conditions ( $\mathrm{LiCl}, \mathrm{DBU}$ ) in acetonitrile. After global deprotection with HF.pyridine and $\mathrm{HCl},(-)$-marinisporolide C (1) was achieved in 25 steps (longest linear sequence) with $1.15 \%$ overall yield.

\subsubsection{Formation of Small- to Medium-Sized Rings}

The selective synthesis of small (3-5) and mediumsized (6-13) ring systems are still a challenge in total synthesis. ${ }^{66}$ The HWE reaction has been applied in the formation of many five- and six-membered ring systems as shown in the following three examples.

In 2015, Brimble and co-workers employed a one-pot benzoyl transfer-intramolecular HWE reaction as a key step in the construction of cis- $\gamma$-hydroxycarvone-based building blocks, which are important intermediates in the synthesis of sesterterpenoid natural products (Scheme 6). ${ }^{67}$

The synthesis of the key starting material allylsilane $\mathbf{9 8}$ was accomplished in a 6-step synthesis from 92 and 93 via a sequence of diastereoselective conjugate addition, nucleophilic phosphonate addition, and the key benzoyl transferintramolecular HWE reaction to construct the cyclohexenone 98. Subsequent transformation into an allyl bromide allowed Barbier coupling with farnesal and subsequent deprotection of the benzoyl group yielded phorbin A (100) and its $\mathrm{C4}$ '-epimer 99. This synthetic approach showed that benzoyl enol ethers could serve as a masking group of $\beta$-ketophosphonates and allow a one-pot benzoyl transferintramolecular HWE reaction. The same protocol was also applied in the synthesis of sesterterpenoid natural products, such as phorbaketal A, which showed selective activity against a range of cancer cell lines. ${ }^{68}$

In the same year, Hiemstra and co-workers described the total synthesis of sesquiterpene lactone aquatolide (107), which was isolated from Asteriscus aquaticus

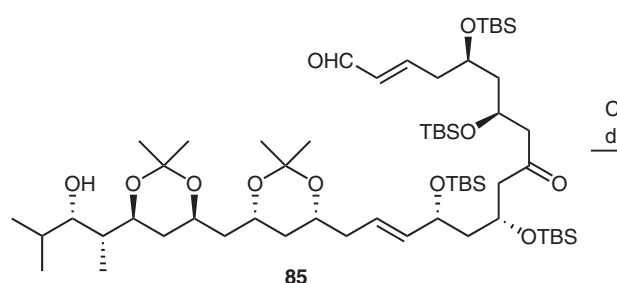

85
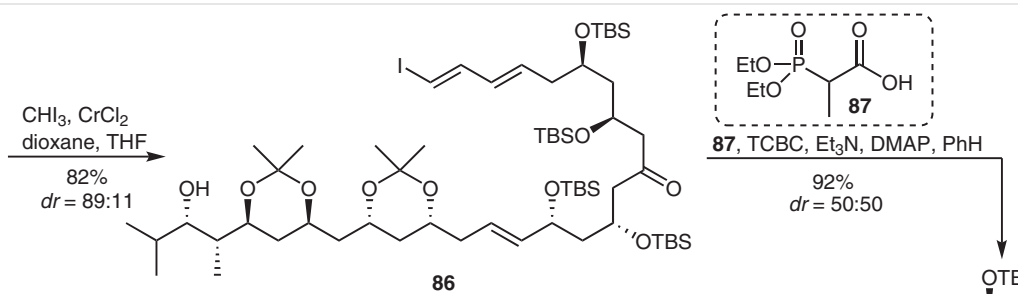

86
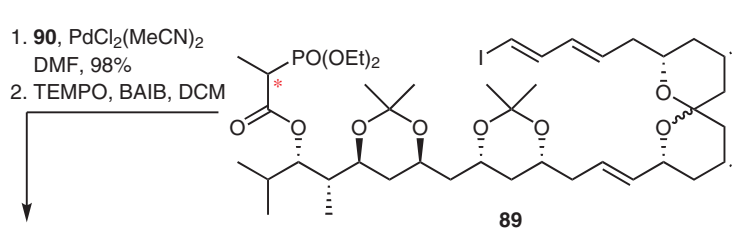

1. HF.py, THF
$\stackrel{\text { 2. TBSOTf, } 2,6 \text {-lutidine, DCM }}{\frac{87 \% \text { (over } 2 \text { steps) }}{\text { Th }}}$<smiles>CCOCCOC(=O)C(C)OC(=O)C(C)[C@H](C)[C@H]1C[C@H](C)OC(C)(C)O1</smiles>

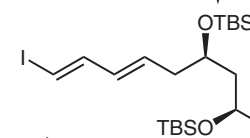<smiles>CC1(C)OCCCC/C=C/[C@H](O)C[C@@H](O)CC(=O)CCCCCCCCCCO1</smiles>

88

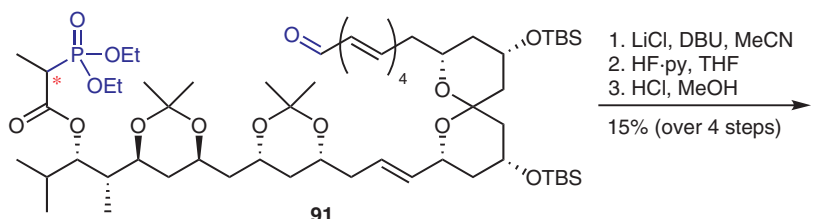<smiles></smiles> 

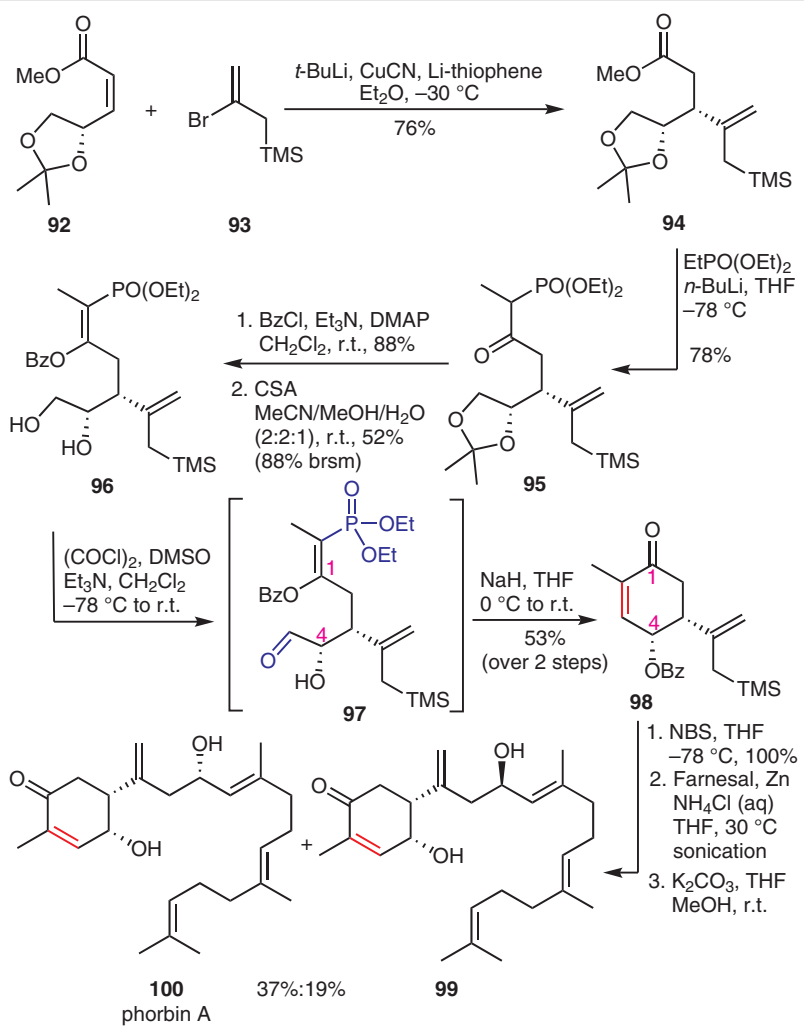

Scheme 6 Synthesis of phorbin A and its C-4' epimer by Brimble and co-workers

(Scheme 7). ${ }^{69}$ The total synthesis started with a cross-aldol reaction of isobutyraldehyde (101) and propynal (102) followed by treatment with trimethyl orthoformate yielding acetal 103. The intramolecular HWE-based cyclization was introduced after esterification with phosphonate 104 by treatment with an excess of $\mathrm{NaH}$ ( 1.5 equiv) under diluted conditions $(0.02 \mathrm{M})$ to form pentenolide 106 in 76\% yield. The synthesis required 11 more steps, including Crabbé homologation to an allene, photochemical [2+2]-cycloaddition, hydroboration, intramolecular Mukaiyama-type aldol reaction to cyclize the eight-membered ring, Dess-Martin oxidation, and Lewis acid catalyzed cyclization of silyl enol ether to yield racemic aquatolide (107) (16 steps, longest linear chain) with an overall yield of $2.2 \%$.

Jeon and Han accomplished the first total synthesis of (-)-flueggenine C (5) (Scheme 8) in 2017,70a which belongs to the plant-derived securinega alkaloids family. ${ }^{71}$

Their synthesis started with the conversion of Boc-protected D-proline $\mathbf{1 0 8}$ in 8 steps. This included diastereoselective Rauhut-Currier (RC) reaction to acetylated dimer 109. ${ }^{72}$ The tertiary alcohols were both esterified by slow addition of diethylphosphonoacetic acid to $\mathbf{1 0 9}$ in the presence of DCC affording phosphonate $\mathbf{1 1 0}$ in 51\% yield. The phosphonate 110 was then converted into olefin 111 via an intramolecular HWE using $\mathrm{NaH}$ as base that was followed

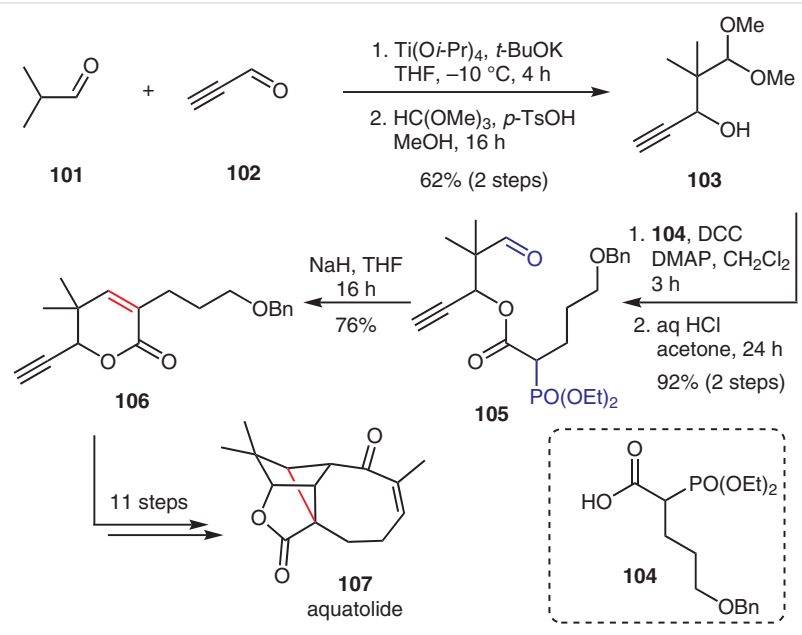

Scheme 7 Total synthesis of aquatolide by Hiemstra and co-workers

by methanolic deacetylation. Subsequent treatment of alcohol 111 with methanesulfonyl chloride and triethylamine followed by TFA-induced Boc-deprotection and final basic treatment (aq $\mathrm{K}_{2} \mathrm{CO}_{3}$ in THF) resulted in (-)-flueggenine $\mathrm{C}$ (5).

\subsection{Synthesis of $\alpha, \beta$-Unsaturated Carbonyl Groups}

$\alpha, \beta$-Unsaturated esters and enones are common motifs in chemical building blocks and natural products. Here, we highlight five recent natural product syntheses that required the introduction of $\alpha, \beta$-unsaturated carbonyl groups via HWE reactions.

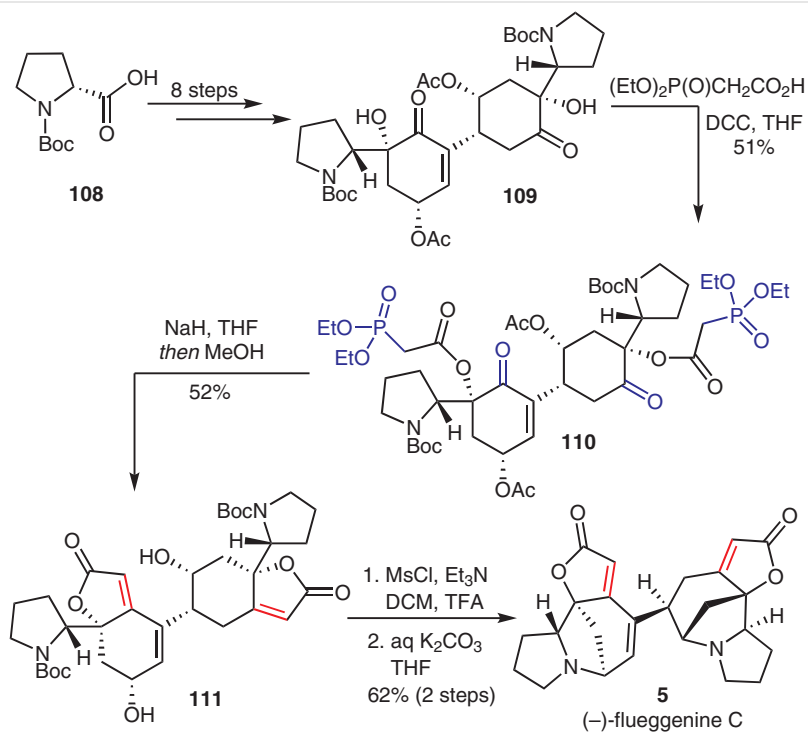

Scheme 8 Synthesis of (-)-flueggenine C by Jeon and Han 
The first example is pinolide (117), which is a member of naturally occurring decanolides isolated in $2012^{73}$ and was synthesized in 2016 by Shelke and Suryavanshi (Scheme 9). ${ }^{74}$ The synthesis started with asymmetric $\alpha$-aminooxylation of pentanal (112) using L-proline and nitrosobenzene as an electrophilic oxygen source. $\alpha$-Anilinooxy aldehyde 113 was subjected to HWE olefination ( $\mathrm{LiCl}$ and $\mathrm{DBU}$ ) in the second step with phosphonoacetate $\mathbf{2 0}$ to yield $\gamma$-anilinooxy- $\alpha, \beta$-unsaturated ester 114, which underwent copper-mediated $\mathrm{N}-\mathrm{O}$ bond cleavage to produce secondary alcohol 115 in 77\% yield (99\% ee). Total synthesis of pinolide $\mathbf{1 1 7}$ was accomplished in 10 additional steps.

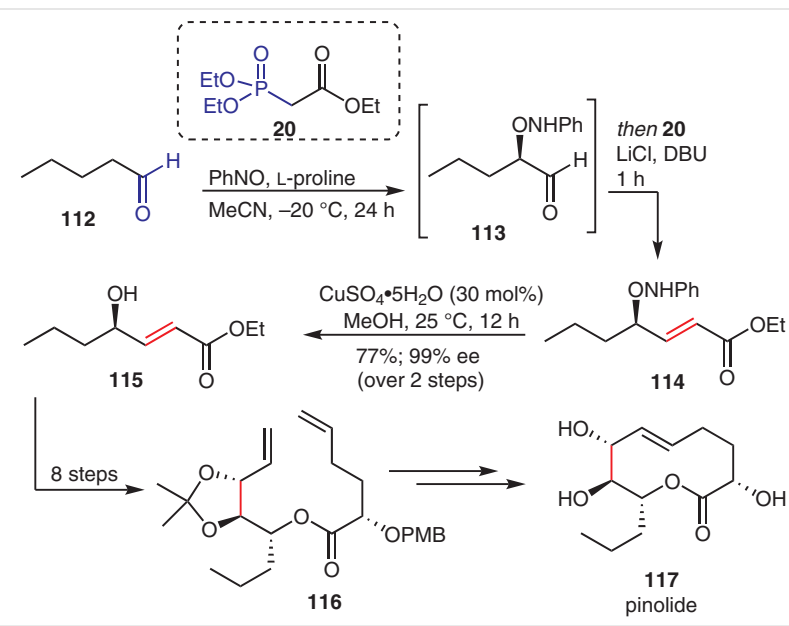

Scheme 9 Total synthesis of pinolide by Shelke and Suryavanshi

In the 2016 total synthesis of nakadomarin A by Boeckman and co-workers, an HWE reaction was employed to construct necessary building blocks. ${ }^{23}$ Nakadomarin A belongs to the manzamine alkaloid family and was isolated from marine sponges by Kobayashi and co-workers. ${ }^{75} \mathrm{Mem}$ bers of this compound family exhibit a broad range of bioactivities, such as cytotoxicity, antimicrobial, antileishmanial, antimalarial, and many more. ${ }^{76}$

As shown in Scheme 10, transformation of aldehyde $\mathbf{1 1 8}$ and phosphonate $\mathbf{3 0}$ under Masamune and Roush conditions $\left(\mathrm{LiCl} / \mathrm{Et}_{3} \mathrm{~N}\right)$ resulted in the formation of the $\alpha, \beta$-unsaturated ketone 31 in $90 \%$ yield. ${ }^{25}$ A second reaction sequence started with the dianion of phosphonate $\mathbf{2 4}$ being propargylated and converted into enone $\mathbf{1 2 0}$ via an HWE olefination with 1,3-diacetoxyacetone (55\% yield over 2 steps). After deprotection and Swern oxidation the resulting furancarbaldehyde 121 was again subjected to an HWE reaction with iminophosphonate $\mathbf{5 4}$ in the presence of LDA and subsequent deprotection yielded $\mathbf{5 5}$. With both 119 and $\mathbf{5 5}$ building blocks in hand, the total synthesis of (-)-nakadomarin $\mathrm{A}(\mathbf{1 2 2})$ was accomplished in 17 steps (longest linear sequence) with an overall yield of $3 \%$.
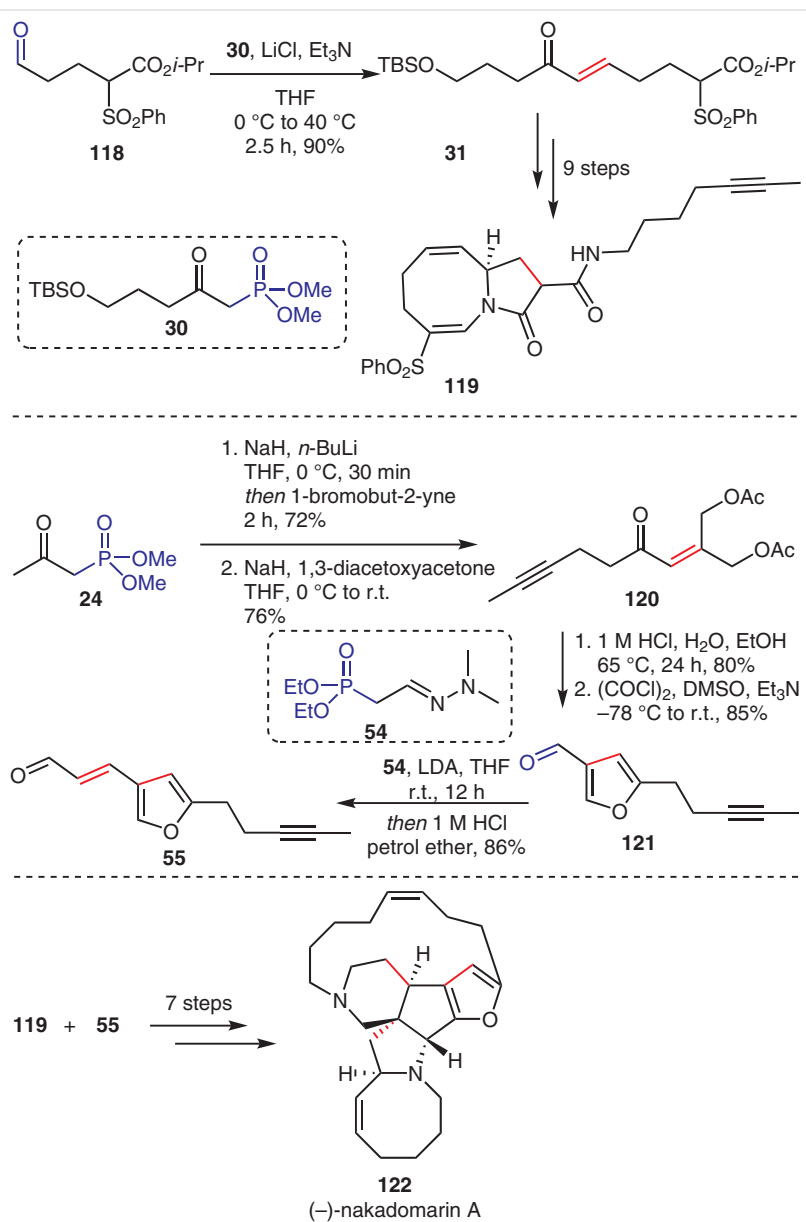

Scheme 10 Synthesis of (-)-nakadomarin A by Boeckman and coworkers

Another example for the use of Masamune and Roush's HWE conditions for the synthesis of linear unsaturated carbonyl units in a natural product synthesis was described in 2017 by Scheidt and co-workers. ${ }^{77}$ They reported the total synthesis of four sesquiterpenoids belonging to the protoilludane, mellolide, and marasmane families (Scheme 11). The synthesis of these bioactive natural products was based on an HWE olefination of aldehyde $\mathbf{1 2 3}$ with phosphonate 124 in the presence of $\mathrm{LiCl}$ and DIPEA, which produced enone 125 in good overall yield (70\%). Intramolecular reductive pinacol coupling was subsequently employed to synthesize the key intermediate cis-cyclobutanediol 126. The total synthesis of echinocidin D (127) was accomplished by desilylation of $\mathbf{1 2 6}$ with tris(dimethylamino)sulfonium difluorotrimethylsilicate (TASF). Intermediate $\mathbf{1 2 6}$ was also used to synthesize isovelleral (130) (3 additional steps), amillaridin (128), and echinocidin B (129). 

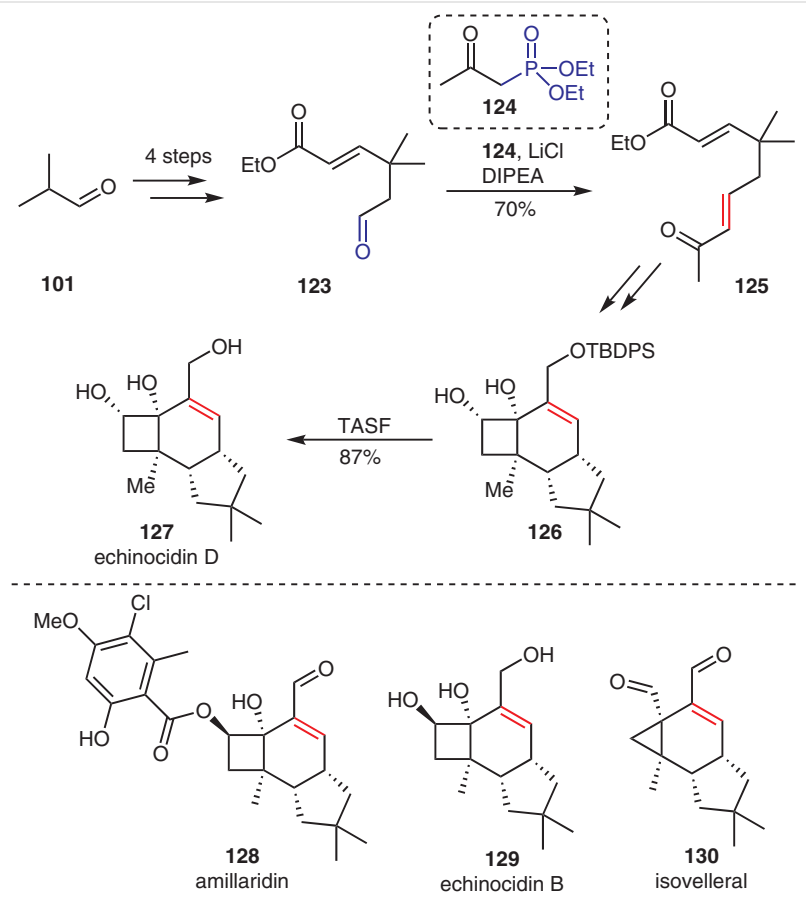

Scheme 11 Synthesis of isovelleral, amillaridin, and echinocidins B and $\mathrm{D}$ and by Scheidt and co-workers

Takasu and co-workers also described the synthesis of protoilludane sesquiterpenes melleolide (13), melleolide $\mathrm{F}$ (132), echinocidins B (136) and D (134) (Scheme 12). ${ }^{18}$ Here, an HWE reaction of ketoaldehyde $\mathbf{1 3 1}$ with phosphonate $\mathbf{6 0}$ yielded $\alpha, \beta$-unsaturated thioester $\mathbf{6 1}$ (78\% yield over 2 steps). Subsequent intramolecular Morita-BaylisHillman reaction with trimethylphosphine yielded the cyclized precursor 133.

The synthesis of protoilludane by Takasu and co-workers was accomplished by using a redox sequence including a Corey-Kim oxidation to cyclobutanone, reduction with $\mathrm{NaBH}(\mathrm{OAc})_{3}$ to 135 , esterification of the alcohol with orsellinic acid, and Fukuyama reduction of the thioester to obtain melleolide (13). Reduction of the aldehyde $\mathbf{1 3}$ with $\mathrm{NaBH}_{4}$ yielded melleolide $F(\mathbf{1 3 2})$. The synthesis of other natural products of the protoilludane family from intermediate $\mathbf{1 3 3}$ was also achieved. This includes echinocidin $\mathrm{D}(\mathbf{1 3 4})$ by reduction and desilylation with lithium aluminum hydride and echinocidin $B(\mathbf{1 3 6})$ from reduction of intermediate 135 with $\mathrm{LiAlH}_{4}$.

Kongkathip and co-workers described the asymmetric total synthesis of (-)-epiquinamide (144) in 2019, ${ }^{78 a}$ which is a quinolizidine alkaloid isolated from the skin of an Ecuadorian frog ${ }^{78 b}$ (Scheme 13). Quinolizidines are an important group of natural products, which show a broad range of biological activity. For the total synthesis, furanoside 137, ${ }^{79}$ derived from D-glucose, was subjected to a Zn-mediated Bernet-Vasella reaction. The resulting aldehyde $\mathbf{1 3 8}$ was

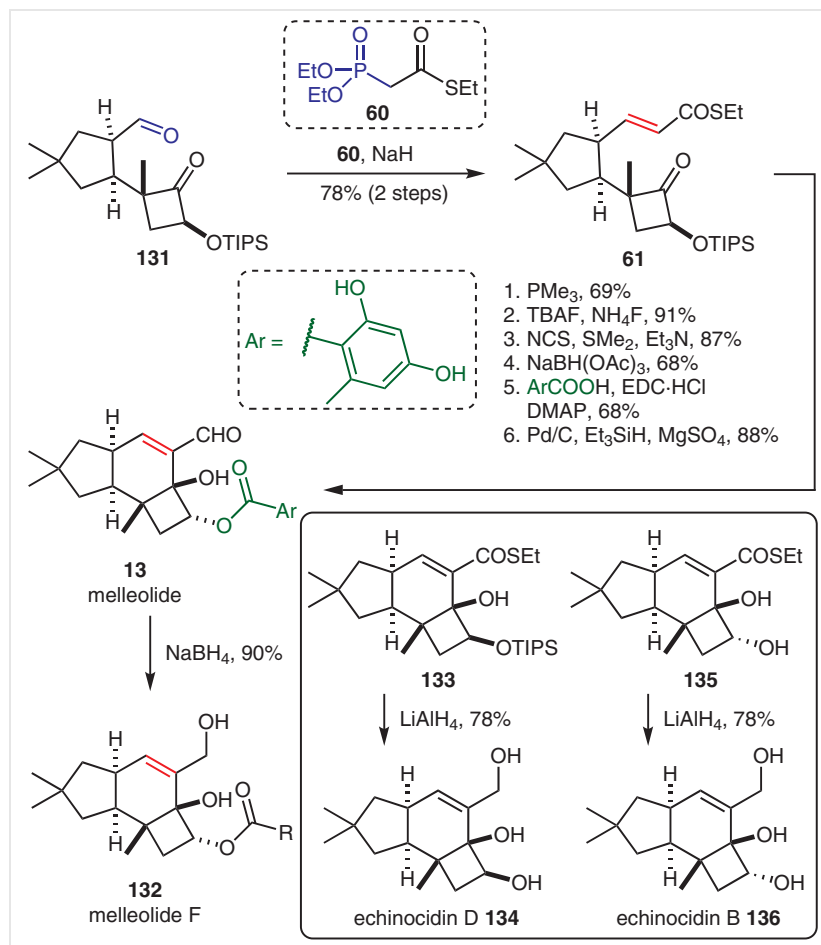

Scheme 12 Total synthesis of melleolide, melleolide $F$, and echinocidins $\mathrm{B}$ and $\mathrm{D}$ by Takasu and co-workers

subjected to an HWE reaction with $\mathbf{2 0}$ in the presence of $\mathrm{NaH}$ in toluene to obtain unsaturated ester $\mathbf{1 3 9}$ in 63\% yield (2 steps). After reduction of ester $\mathbf{1 3 9}$ to a primary alcohol and silyl-protection, the secondary alcohol was transformed into the respective azide $\mathbf{1 4 0}$ under Mitsunobu conditions with inversion of the stereocenter. Mesylation of the alcohol and intramolecular carbamate $N$-alkylation after cleavage of silyl group with TBAF resulted in 2,3-cis-disubstituted piperidine 141. Boc-deprotection and coupling of the amine with but-3-enoic acid provided diene 142, which was subjected to ring-closing metathesis using the 2nd generation Hoveyda-Grubbs catalyst yielding an unsaturated quinolizidinone. The total synthesis of (-)-epiquinamide (144) was completed by hydrogenation of the saturated amine 143, followed by $N$-acetylation and reduction of lactam with $\mathrm{BH}_{3} \cdot \mathrm{SMe}_{2}$ complex.

\subsection{Synthesis of Substituted C=C Bonds}

The following two examples illustrate the formation of substituted doubles bonds by HWE olefinations.

Lindsley and co-workers described the formal total synthesis of pericoannosin A (12) in 2019 (Scheme 14), ${ }^{80}$ which was isolated in 2015 from Periconia sp. F31 as a new PKSNRPS hybrid metabolite with a 3-(hexahydro- $1 \mathrm{H}$-isochromen-3-yl)-5-isobutylpyrrolidin-2-one core structure. ${ }^{81}$ The new synthetic route included an HWE reaction to install the substituted olefin and required fewer steps with 


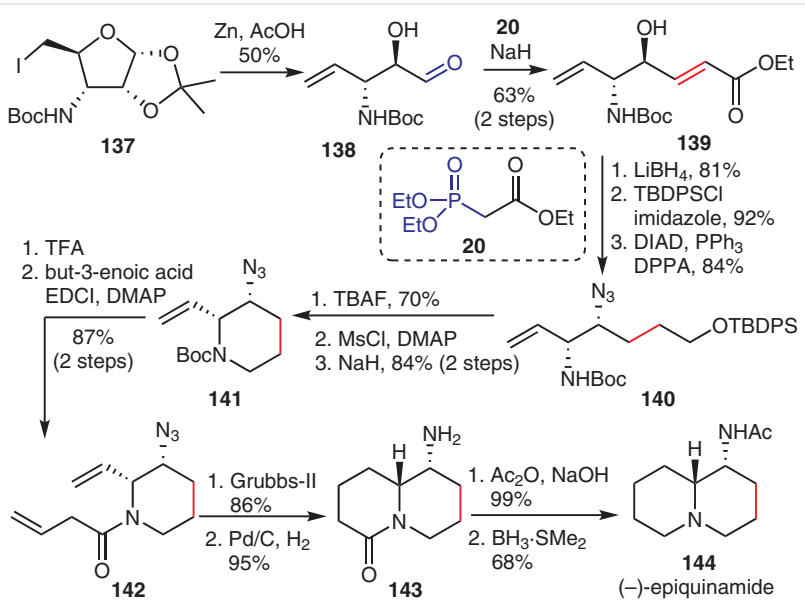

Scheme 13 Total synthesis of (-)-epiquinamide by Kongkathip and coworkers

improved overall yield in comparison to the total synthesis of 12 described by Lücke, Kalesse, and co-workers in $2018 .^{82}$ In short, an asymmetric Diels-Alder reaction with 145 and isoprene (146) yielded an $\alpha, \beta$-unsaturated aldehyde, which was subjected to a Wittig reaction to give terminal alkene 147. The corresponding $\beta$-ketophosphonate 149 was obtained by treatment of $\mathbf{1 4 7}$ with excess lithiated diethyl ethylphosphonate $\mathbf{1 4 8}$ in 91\% yield. An HWE reaction of acetaldehyde with phosphonate 149 and $\mathrm{Ba}(\mathrm{OH})_{2}$ as base produced enone $\mathbf{1 5 0}$ in $\mathbf{8 1} \%$ yield. A Felkin-Anh stereoselective reduction of enone $\mathbf{1 5 0}$ with DIBAL-H afforded the secondary alcohol. Protection of the alcohol followed by selective hydroboration of the terminal alkene and basic oxidizing work-up resulted in an alcohol, which underwent DessMartin oxidation to aldehyde $\mathbf{1 5 1 .}$

Anaenamides A (14) and B (155) are new anticancer cyanobacterial depsipeptides containing a chlorinated pharmacophore and were isolated from a marine cyanobacterium derived from the Anae Island reef system in Guam in $2020 .^{31}$ Their scaffold has an unusual $\alpha$-chlorinated $\alpha, \beta$-un-

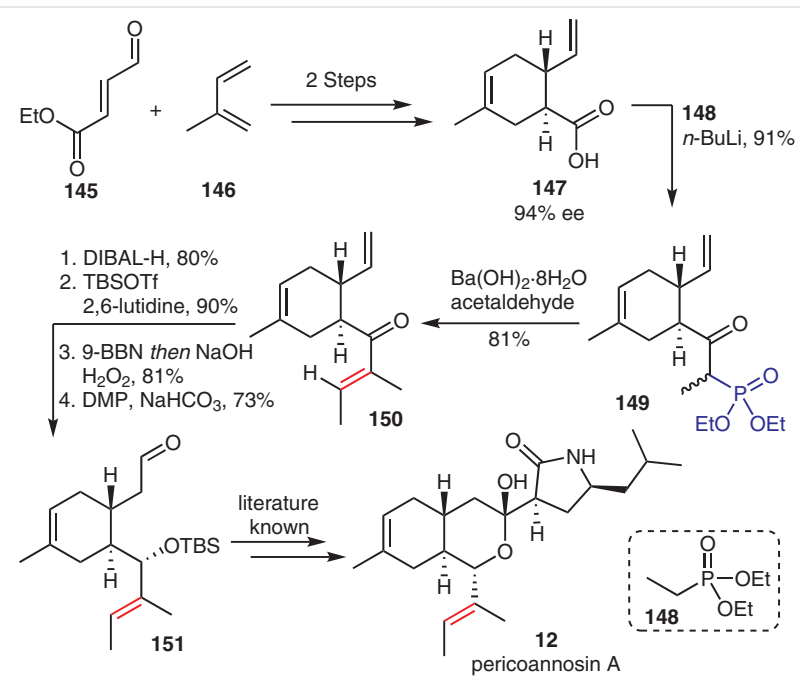

Scheme 14 Formal synthesis of pericoannosin A by Lindsley and coworkers

saturated ester and its double bond geometry impacts the cytotoxicity. Luesch and co-workers achieved the synthesis of anaenoic acid (154) in 9 steps that included an HWE reaction to introduce the vinyl halide moiety (Scheme 15). ${ }^{31}$ Building blocks 153a and 153b were synthesized from commercially available 152 and phosphonate 45 via HWE olefination, followed by Boc deprotection under acidic conditions. Final coupling of anaenoic acid (154) with a crude mixture of 153a and 153b by the use of EDC, HOBt, and DIPEA led to the $E$ - and $Z$-isomers ( 14 and $\mathbf{1 5 5}$, respectively) of anaenamide.

Goswami and co-workers described the first total synthesis and stereochemical assignment of penicitide A (163) in 2020, which is a marine secondary metabolite (Scheme 16). ${ }^{36}$ Penicitide A (163) was isolated from a marine red algal species by Wang and co-workers in 2011 and showed moderate cytotoxicity against pathogen Alternaria brassicae and human hepatocellular liver carcinoma cell lines. ${ }^{83}$

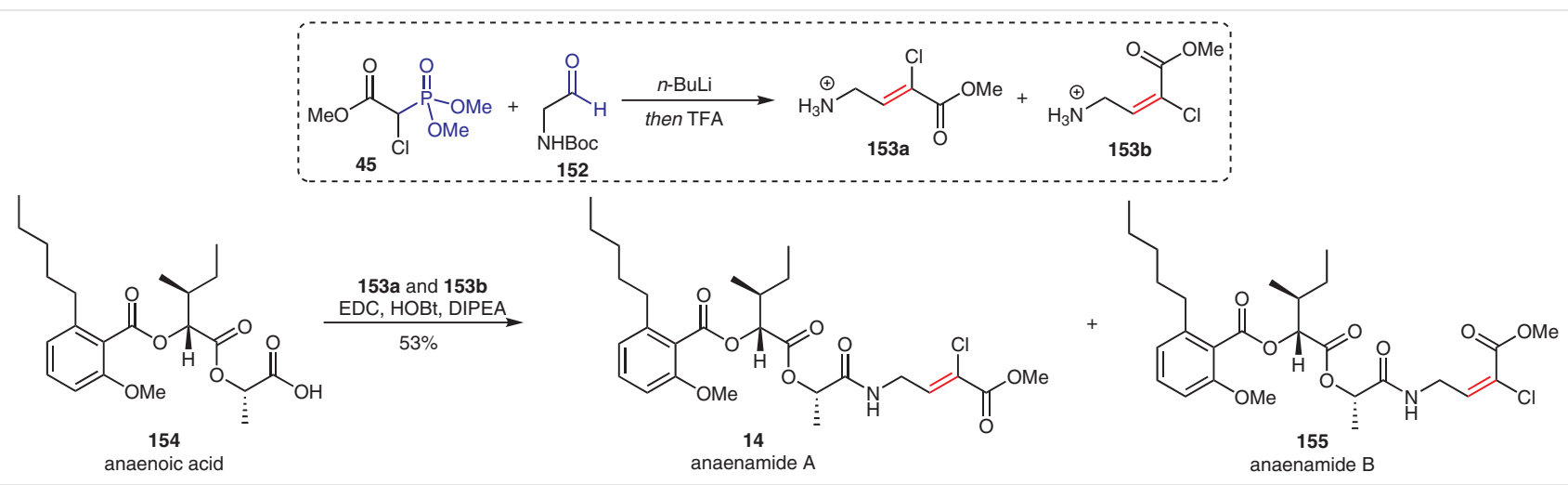

Scheme 15 Total synthesis of anaenamides A and B by Luesch and co-workers 


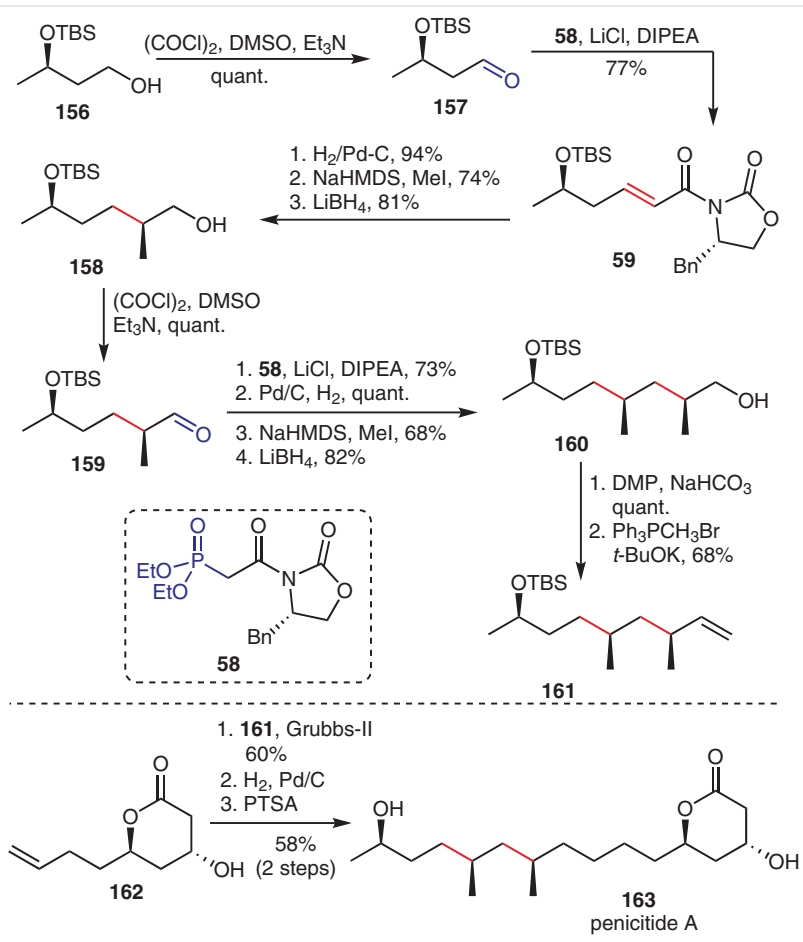

Scheme 16 Total synthesis of penicitide A by Goswami and co-workers

The syntheses commenced with alcohol 156, which was first subjected to Swern oxidation and the resulting aldehyde 157 transformed by an HWE olefination with phosphonate $\mathbf{5 8}$ in the presence of $\mathrm{LiCl}$ and DIPEA to obtain primarily $E$-isomer $\mathbf{5 9}$ in 77\% yield. Alcohol 158 was obtained after hydrogenation, Evans methylation, and reduction with $\mathrm{LiBH}_{4}$. After another Swern oxidation aldehyde 159 was treated again with phosphonate $\mathbf{5 8}$ under Masamune and Roush conditions ( $\mathrm{LiCl}$, DIPEA) yielding the olefin in $73 \%$. A second sequence of Evans methylation and reduction following hydrogenation resulted in compound 160. A final
Dess-Martin oxidation and one carbon Wittig olefination led to the first building block 161. Alkenes 161 and 162 were subjected to cross olefin metathesis, hydrogenation, and deprotection to obtain penicitide A (163) in 15 linear steps with an overall yield of $4.3 \%$. Their synthesis allowed a divergent synthetic approach with easy access to all possible stereoisomers, which led to confirmation of the stereochemical assignments in penicitide A (163).

\subsection{Late-Stage Modifications by HWE Reactions}

Indoxamycins $\mathrm{A}-\mathrm{F}$ were isolated in 2009 from a saline culture of marine-derived actinomyces by Sato and coworkers as new members of the polyketide structure class. ${ }^{84}$ The structure elucidation of indoxamycins revealed a highly congested [5.5.6] tricyclic carbon skeleton featuring an $\alpha, \beta$-unsaturated carboxylic acid side chain and a trisubstituted alkene. The congested core structure consists of six stereogenic centers with three quaternary carbons. This intriguing structure along with the remarkable biological activity makes the indoxamycin family a captivating target for total synthetic approaches.

Liang and co-workers successfully used the HWE reaction in 2019 to install an $\alpha, \beta$-unsaturated ester at a late stage in the total synthesis of (-)-indoxamycins A (11) and $\mathrm{B}(\mathbf{1 6 9}){ }^{85}$

The synthesis of indoxamycins required the generation of 165 from $(R)$-carvone 164 (Scheme 17). This was done in 10 steps including acylation under $\mathrm{KH} /$ dimethyl carbonate conditions, methylation of the generated potassium enolate salt, addition of Comins' reagent, and Pd-catalyzed reductive detriflation.

HWE olefination with 166, phosphonate 167, and $\mathrm{NaH}$ followed by in situ removal of the tert-butyl group resulted in the formation of (-)-indoxamycin A (11) in 92\% yield. A similar procedure was applied for the synthesis of indoxamycin B (169). Reduction and oxidation were used to obtain

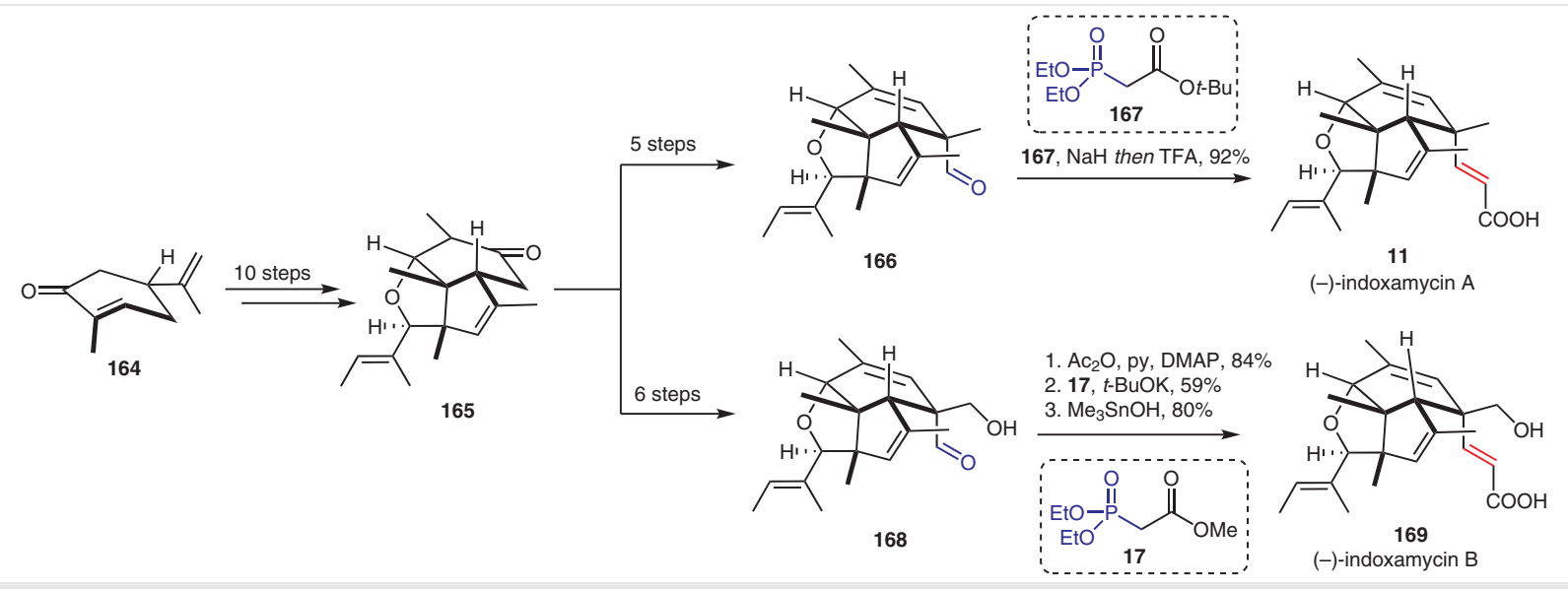

Scheme 17 Total synthesis of (-)-indoxamycins A and B by Liang and co-workers 


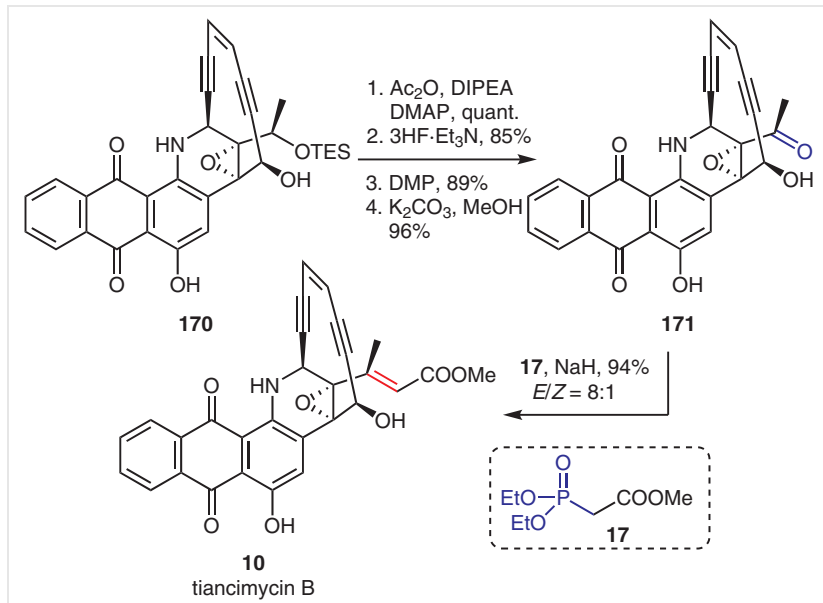

Scheme 18 Total synthesis of tiancimycin B by Nicolaou and co-workers

aldehyde 168. Next acetylation of the primary alcohol was followed by HWE reaction with phosphonate $\mathbf{1 7}$ to give the product with low conversion due to steric hindrance around the aldehyde. Several bases were screened $(\mathrm{NaH}$, $n$-BuLi, and $t$-BuOK) and $t$-BuOK was relatively effective in the HWE reaction giving the corresponding unsaturated ester in 59\% yield. Simultaneous hydrolysis of the methyl ester and acetyl group removal with $\mathrm{Me}_{3} \mathrm{SnOH}$ led to (-)-indoxamycin B (169).

Another example for late-stage introduction of $\alpha, \beta$-unsaturated esters using HWE reactions was reported in 2020 by Nicolaou and co-workers in the total synthesis of tiancimycin B (10) (Scheme 18). ${ }^{16}$ TES-protected uncialamycin $\mathbf{1 7 0}$ was synthesized in 2016 from hydroxyisatin in 22 steps. ${ }^{86}$ It was transformed to uncialamycin analogue $\mathbf{1 7 1}$ in four steps with a newly introduced ketone moiety. HWE

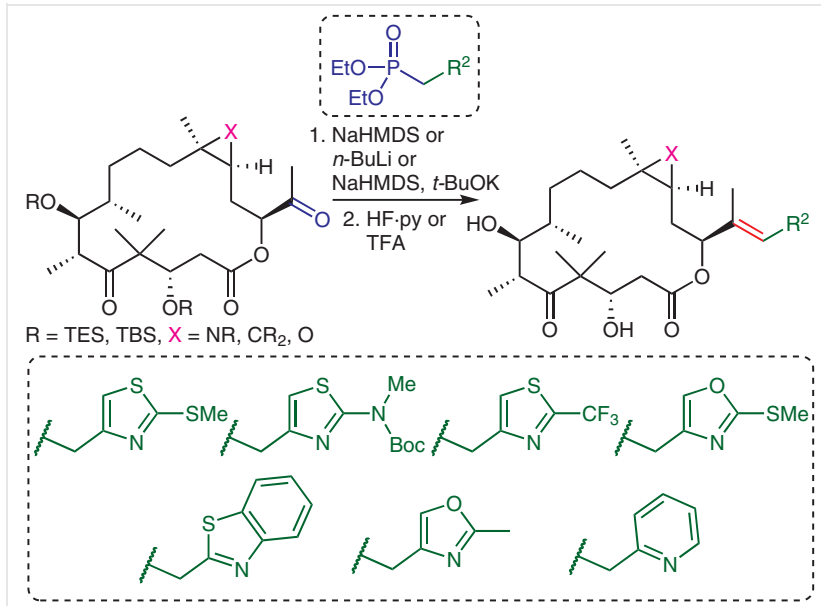

Scheme 19 Synthesis of epothilone B analogues by Nicolaou and coworkers olefination of $\mathbf{1 7 1}$ with phosphonate $\mathbf{1 7}$ and $\mathrm{NaH}$ as a base provided the $E$ - and $Z$-isomers of tiancimycin B (10) in $84 \%$ and $10 \%$ yield, respectively.

Late-stage HWE olefinations were also used in the modification of epothilone B analogues designed by Nicolaou and co-workers to improve their potencies and pharmacological properties as anticancer drugs (Scheme 19). ${ }^{35}$ Introduction of different heterocycle side chains to the macrocyclic core was achieved via HWE reactions in the presence of NaHMDS, $n$-BuLi, or NaHMDS/t-BuOK, followed by desilylation.

\subsection{HWE Reactions on Solid Supports}

Solid phase synthesis (SPS) is mainly applied in the synthesis of longer and difficult to purify peptides and nucleotides. However, this method has increasingly been used for SP-supported HWE reactions in the synthesis of other small molecules. ${ }^{87}$ Most notably, the synthesis of $\alpha, \beta$-unsaturated amides, ${ }^{88}$ esters and nitriles, ${ }^{89}$ macrocycles, ${ }^{90}$ olefins, ${ }^{91}$ triazolopyridazines, and peptides containing $E$-alkene amide linkages have been reported. ${ }^{92}$ Furthermore, several reports on the synthesis of $Z$ - $\alpha, \beta$-unsaturated esters, ${ }^{93}$ solvent-free reactions, ${ }^{94}$ and crosslinking polysulfones under phase transfer catalysis (PTC) ${ }^{95}$ have been published.

Beemelmanns and co-workers reported the application of SP-based HWE reagents to prepare the vinylogous amino acid containing natural product barnesin A (177) (Scheme 20), ${ }^{96}$ which was previously isolated from anaerobic bacte-

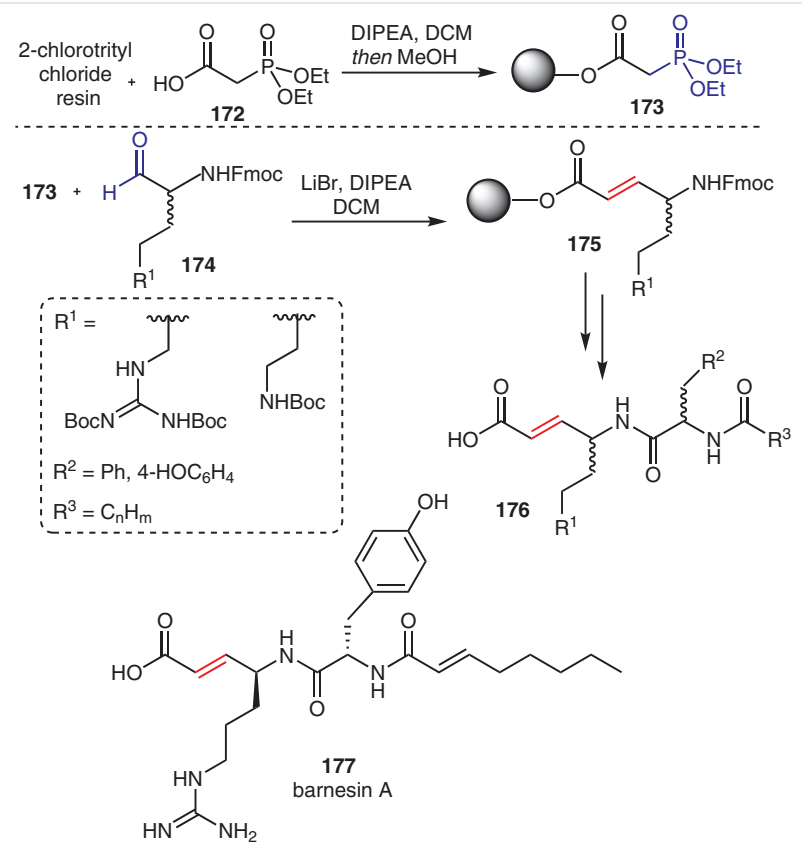

Scheme 20 Solid-phase based synthesis of cysteine proteases inhibitor barnesin $\mathrm{A}$ and derivatives by Beemelmanns and co-workers 
rium Sulfurospirrilum barnesii as the first secondary metabolite from Epsilonproteobacteria and the first NRPS-PKS hybrid molecule from this bacterial family. ${ }^{97}$

The synthesis began with loading a 2-chlorotrityl chloride resin (CTC resin) with diethylphosphonoacetic acid (172), ${ }^{88}$ which served as a linker, and phosphonate for the HWE reaction. Resin-bound phosphonate $\mathbf{1 7 3}$ was deprotonated with DIPEA and subjected to an HWE reaction with Fmoc-protected aldehyde $\mathbf{1 7 4}$ ( $\mathrm{LiBr}$ and DIPEA) yielding solid-bound olefin 175, which allowed for further peptide coupling steps. Subsequent global deprotection produced 14 lipodipeptides with micromolar to nanomolar inhibitory activity against different cysteine proteases.

\subsection{Synthesis of Poly-Conjugated C=C Bonds}

Conjugated $\pi$-bond systems allow delocalization of $\pi$ electrons through alternating single and double bonds. This concept was introduced by Claisen in 1926 and later named vinylogy. ${ }^{98}$ HWE reactions play a central role in the construction of vinylogous systems and polyconjugated double bonds, especially in natural product synthesis as shown in the following eight examples. ${ }^{99,100}$

The polyunsaturated side chain of the alkaloids militarinone D (8) (Scheme 21), isolated in 2003 from Paecilomyces militaris, ${ }^{101}$ was accomplished by Sim and co-workers in 2015 using a sequence of HWE reactions. ${ }^{32}$ The first HWE reaction ( $\mathrm{NaH}$ in THF) of aldehyde $\mathbf{1 7 9}$ with phosphonate $\mathbf{4 7}$ yielded unsaturated ester $\mathbf{4 8}$ in $71 \%$ yield (2 steps, $E / Z$ $1: 2.3)$. A subsequent reduction/oxidation sequence produced the aldehyde as an $E / Z$ mixture where the $Z$-isomer was converted into the $E$-isomer $\mathbf{1 8 0}$ by treatment with catalytic iodine. The second HWE olefination (NaH in THF) of unsaturated aldehyde $\mathbf{1 8 0}$ and phosphonate $\mathbf{3 9}$ yielded triene $\mathbf{4 0}$ in $80 \%$ yield, which was again transformed into aldehyde $\mathbf{1 8 1}$ in a reduction/oxidation sequence. Aldehyde 181 was added to lithiated pyridine 182 in the final sequence and the resulting allylic alcohol was oxidized to a ketone. This was followed by a global MOM removal to complete the synthesis of militarinone D (8) in 5\% overall yield.

A structurally related NRPS-PKS based fungal-derived natural product, fumosorinone $\mathrm{A}(\mathbf{9}),{ }^{102}$ was isolated in 2017, and shown to contain a pentaene moiety attached to a pyrrolidine-2,4-dione. Due to its potent protein tyrosine phosphatase $1 \mathrm{~B}$ inhibitor activity and intriguing structure, it was synthesized in 2018 by Schobert and co-workers (Scheme 22). ${ }^{28}$ The required aldehyde $\mathbf{1 8 3}$ was prepared from commercially available $(S)$-citronellol in 10 steps to synthesize the polyunsaturated PKS side-chain, which was then subjected to the chain elongating HWE reaction with phosphonate $\mathbf{3 9}$ and $\mathrm{NaH}$ as base to produce elongated olefin $\mathbf{4 0}$ in $67 \%$ yield. Ester $\mathbf{4 0}$ was subjected to a reduction/oxidation sequence yielding aldehyde $\mathbf{1 8 1}$, which was

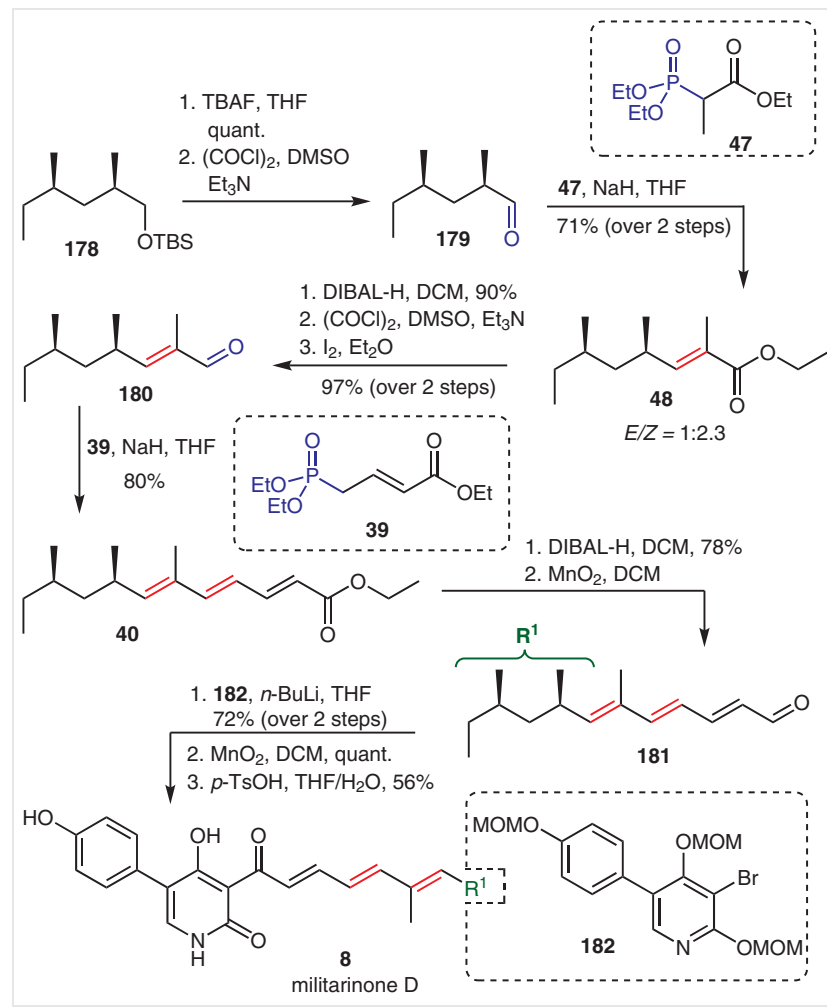

Scheme 21 Total synthesis of militarinone D by Sim and co-workers

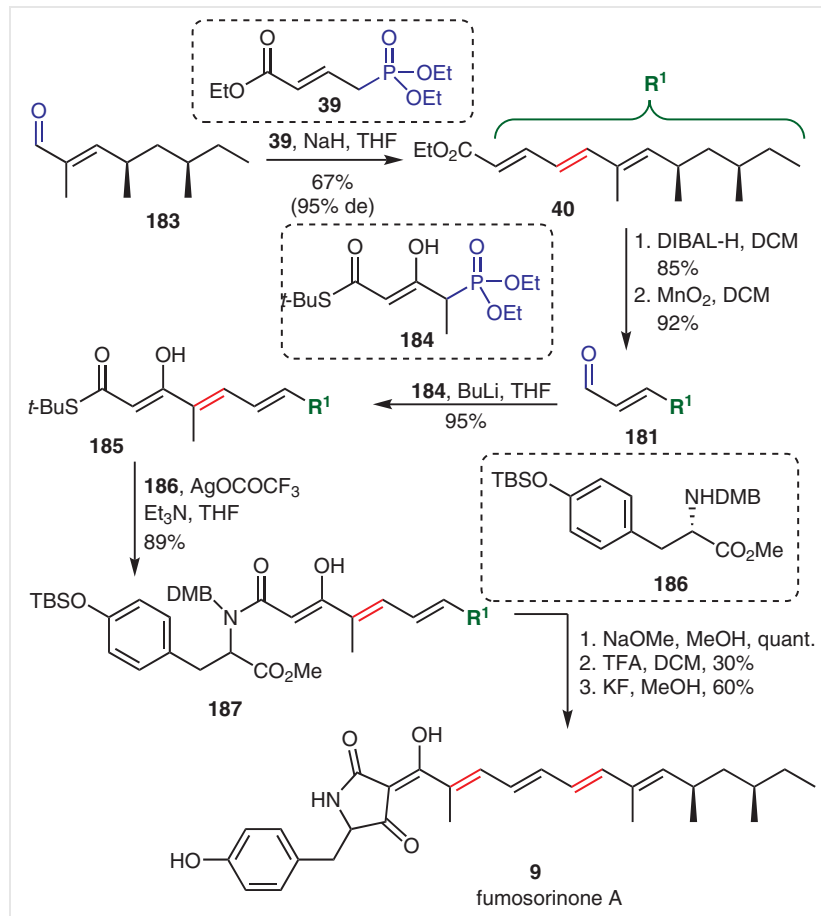

Scheme 22 Total synthesis of fumosorinone A by Schobert and coworkers 
subjected to a second HWE olefination following Loscher's protocol $^{103}$ giving thioester 185 in a 95\% yield as a 2:3 keto/enol mixture. Silver-mediated acylation with amino acid 186 resulted in ketoamide $\mathbf{1 8 7}$. Subsequent cyclizations followed by a partial TBS deprotection with TFA and global desilylation with KF completed the first total synthesis of fumosatinone $\mathrm{A}(\mathbf{9})$.

Another application of an HWE reaction in the synthesis of conjugated $\mathrm{C}=\mathrm{C}$ bonds was described by Gerstmann and Kalesse in their total syntheses of nannocystin Ax (188) and aetheramide A (189) (Scheme 23). ${ }^{104}$ Chiral aldehyde 191 [4 steps from benzaldehyde (190)] was subjected to an HWE reaction using phosphonate $\mathbf{3 6}$ and $n$-BuLi to yield acrylic ester 192 in $96 \%$ yield in favor of the desired $E$-isomer (5.6:1). Ester 192 was reduced and subsequently oxidized to aldehyde 193, which was used in a vinylogous Mukaiyama aldol reaction with acetal 194 in the presence of catalyst

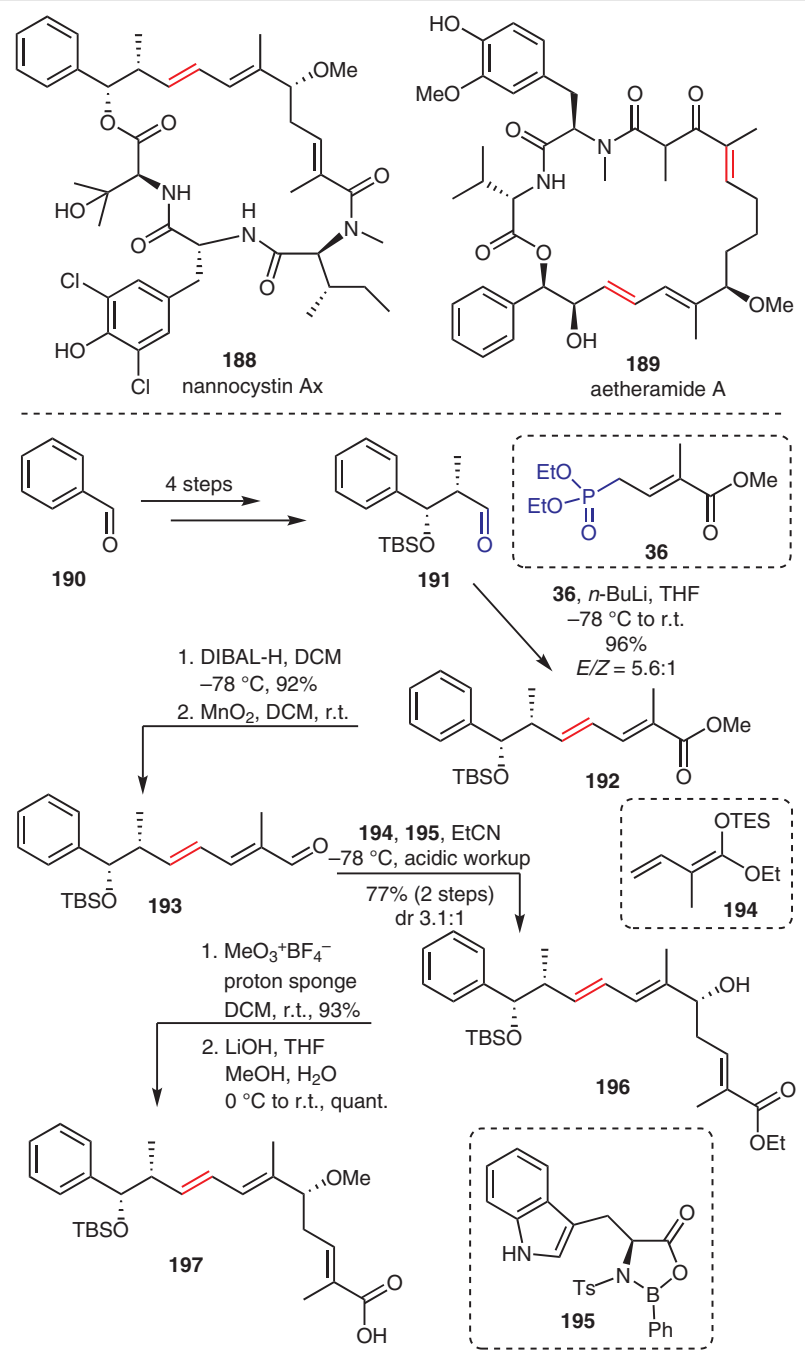

Scheme 23 Structure of nannocystin Ax and aetheramide A and the total synthesis of a building block by Gerstmann and Kalesse
195 to give product 196. The alcohol 196 was then methylated and the ester was hydrolyzed to carboxylic acid 197, which was used for completion of the total synthesis of nannocystin Ax (188).

Similarly, the HWE reaction was used by Mori and coworkers in their total synthesis of brevisamide (203) (Scheme 24), ${ }^{30}$ a natural marine product isolated from dinoflagellate containing a tetrahydropyran (THP) ring incorporated into a conjugated carbon chain.

The synthesis of the unsaturated side chain started from commercial 4-(benzyloxy)butanol, which was converted into diol 198 in 10 steps. A short reaction sequence afforded mono-TBS deprotected alcohol 201. The primary alcohol 201 was oxidized with Dess-Martin periodinane to yield Lindsley's aldehyde 202 as a precursor for the HWE reaction. ${ }^{100 a}, 105$ The olefination of $\mathbf{2 0 2}$ was accomplished using the vinylogous phosphonate 43 and $n$-BuLi at room temperature to provide dienoate $\mathbf{4 4}$ in $62 \%$ yield. Ethyl ester 44 was subsequently reduced to the corresponding alcohol using DIBAL-H. This was followed by desilylation of the secondary alcohol and final oxidation of the primary alcohol with $\mathrm{MnO}_{2}$ gave brevisamide (203).

Hong and co-workers reported an extraordinary synthetic strategy towards the total synthesis of lasonolide A (6) in 2018 (Scheme 25). ${ }^{33}$ This is a natural product contains two functionalized tetrahydropyran moieties and exhibits high and selective cytotoxicity against cancer cells.

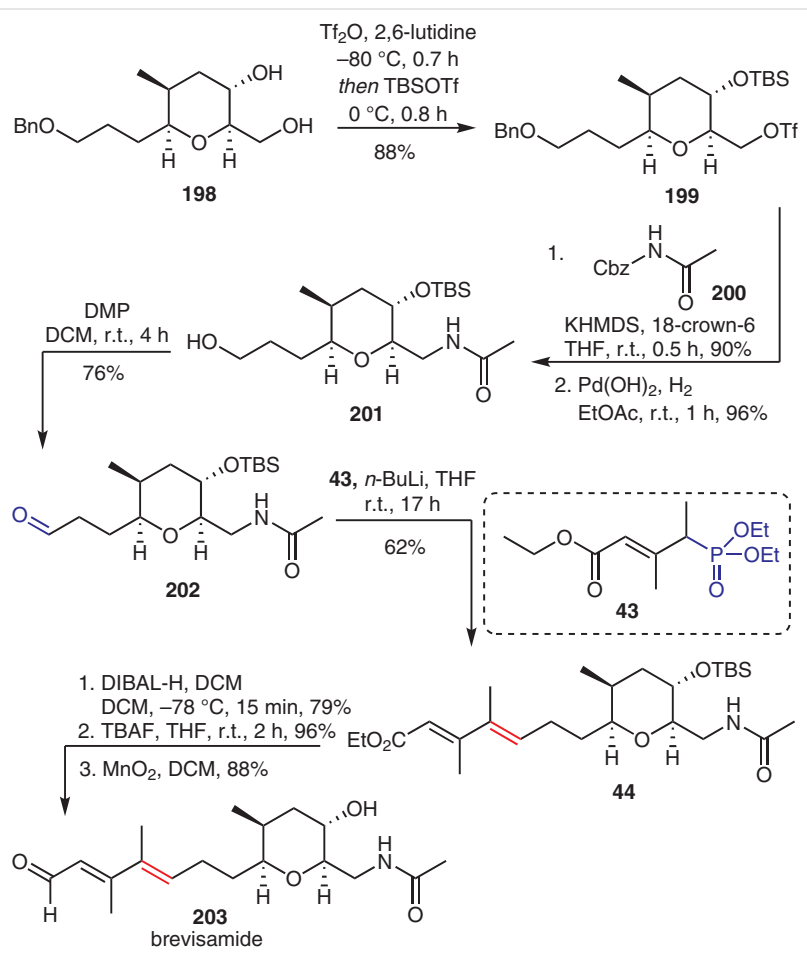

Scheme 24 Synthesis of brevisamide by Mori and co-workers 


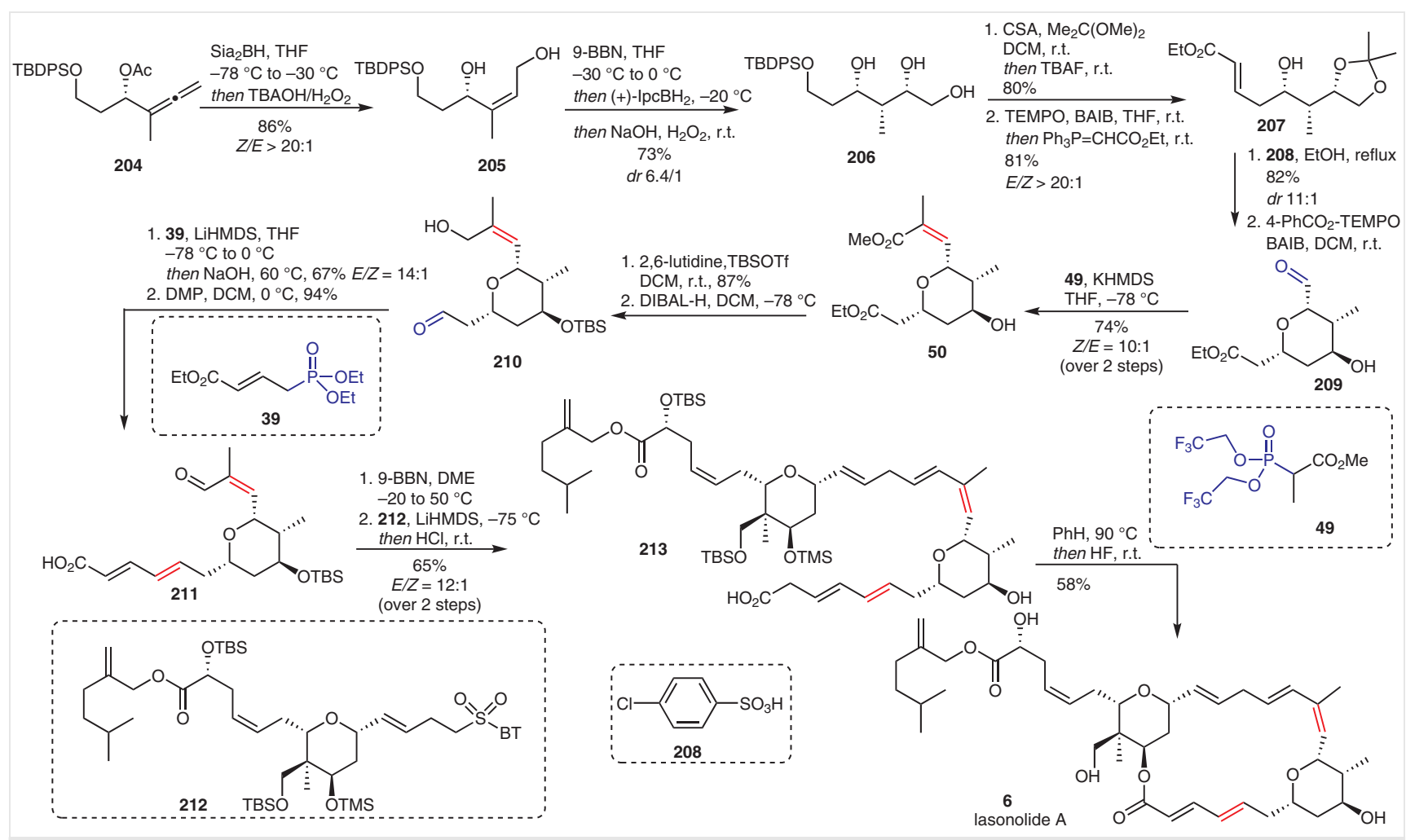

Scheme 25 Total synthetic strategy lasonolide A by Hong and co-workers

A hydroboration-oxidation sequence starting from allene 204 provided polyhydroxy alkane 206 in good overall yields. The alcohol in $\mathbf{2 0 6}$ was first subjected to an oxidation-Wittig elongation sequence to produce ester 207. Acidic tetrahydropyran formation was followed by the oxidation to aldehyde $\mathbf{2 0 9}$ that allowed the first HWE reaction with Still-Gennari phosphonate $\mathbf{4 9}$ yielding trisubstituted cisconjugated methyl ester $\mathbf{5 0}$ in good yields (Z/E 10:1). Silylation of the secondary alcohol in $\mathbf{5 0}$ proceeded smoothly and DIBAL-H mediated reduction of the ester delivered aldehyde 210, which was again subjected to HWE olefination with a vinylogous phosphate $\mathbf{3 9}$ and LiHMDS as a base.

Subsequent Dess-Martin oxidation of the allylic alcohol provided Z-enone 211 in 94\% yield. An unusual 9-BBN complexation of free carboxylic acid allowed successful Julia olefination with sulfone 212 to give 213. Lactonization was employed to complete the total synthesis of (-)-lasonolide $\mathrm{A}(\mathbf{6})$.

The synthesis of polyconjugated mycolactone mimetics by Altmann and co-workers in 2019 represents an addition example for the efficient application of HWE reactions (Scheme 26). ${ }^{106}$ Mycolactones A (227) and B (228) feature a common 12-membered macrolactone core, which can interact with several cellular targets, such as mTor, ${ }^{107}$ Sec61 translocon, ${ }^{108}$ Wiskott-Aldrich syndrome protein, ${ }^{109}$ and the angiotensin II receptor. ${ }^{110}$ Their synthesis targeted mycolactone analogues $\mathbf{2 2 0 , 2 2 5}$, and $\mathbf{2 2 6}$ as configurationally stable mimetics to investigate the importance of the double bond for the activity and the mode of action in Buruli ulcer pathogenesis (Scheme 26).

Their synthesis started from methyl 2-iodobenzoate (214), which was converted into vinyl iodide 215 via Sonogashira coupling with TMS-acetylene, desilylation, reduction of the ester, and zirconium-catalyzed carboalumination/iodination of the terminal alkyne moiety. After oxidation of the primary alcohol 215 with $\mathrm{MnO}_{2}$ the resulting aldehyde was subjected to an HWE reaction with triethyl phosphonoacetate (20) to yield $\alpha, \beta$-unsaturated ester 216 (99\% over 2 steps). Stille coupling of vinyl iodine $\mathbf{2 1 6}$ with stannane $\mathbf{2 1 7}$ followed by saponification gave acid $\mathbf{2 1 8}$. Final esterification with macrolactone $\mathbf{2 1 9}$ and desilylation yielded 220. Analogous syntheses for cyclopentene-derived acids 224 and 225 starting from 2-oxocyclopentane-1-carboxylate (221) and 1,4-bis(hydroxymethyl)cyclohexane were also reported.

The marine secondary metabolite nafuredin B (237) was isolated in 2017 from deep-sea-derived Talaromyces aculeatus and Penicillium variabile together with penitalarins A-C and known nafuredin A. ${ }^{111}$ Nafuredins contain a linear skeleton with an unsaturated chain linked to $\alpha, \beta$-unsaturated lactone and showed cytotoxicity against several cell lines in the micro-molar range thus making them attractive synthetic targets. 
A

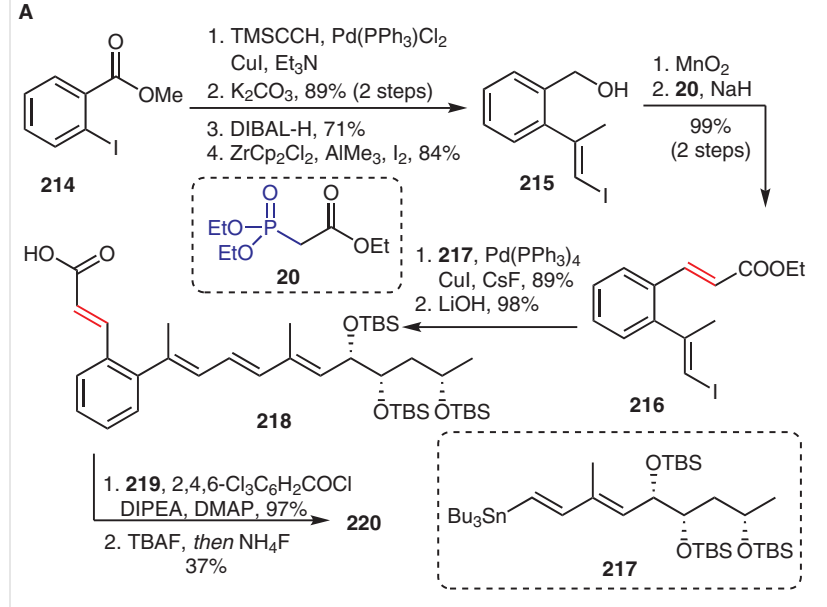

give the secondary alcohol 232. Subsequent oxidation to ketone 233 and an HWE reaction $(\mathrm{NaH})$ with triethyl phosphonoacetate (20) produced the elongated unsaturated side chain in 234 (82\% yield, $E / Z$ 6:1). The final elongation via Julia-Kocienski olefination was pursued after another reduction/oxidation sequence and transformation with sulfone 235 to obtain 236. ${ }^{113,114}$ The last three steps involved treatment with $p$-toluenesulfonic acid to afford a diol, subsequent acrylation, and then ring-closing metathesis provided the desired nafuredin B (237).

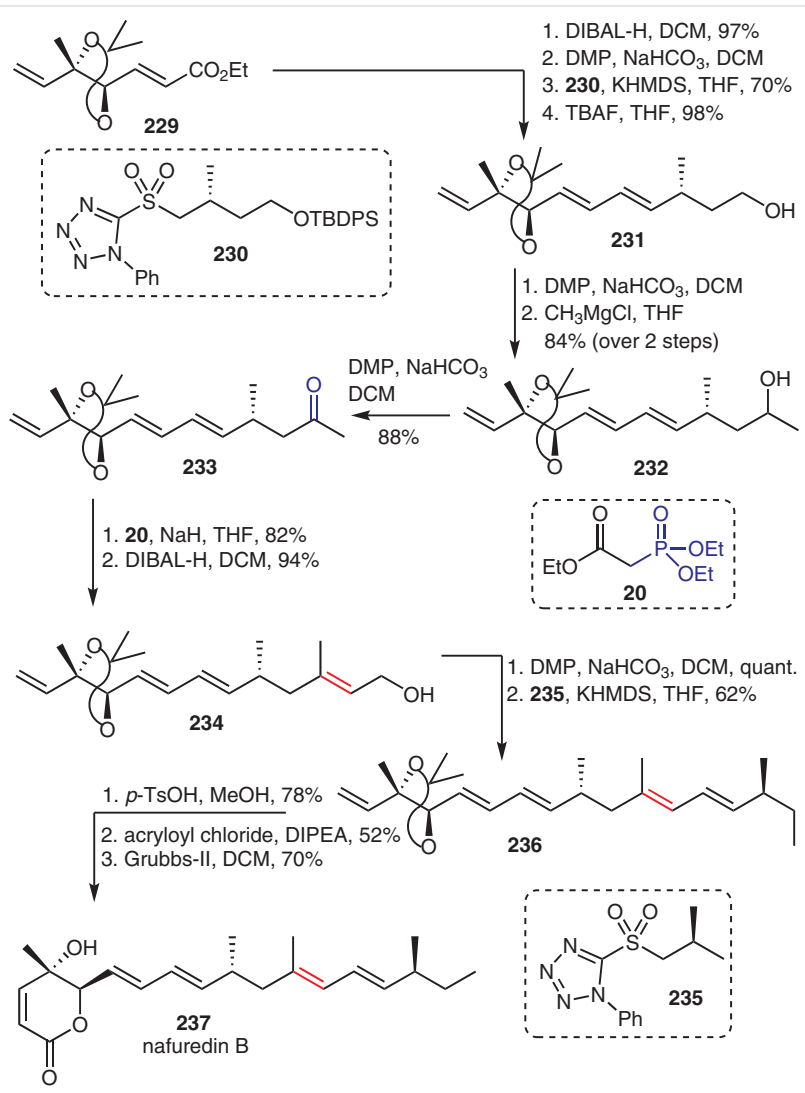

Scheme 27 Total synthesis of nafuredin B by Goswami and co-workers

Scheme 26 Synthesis of mycolactone analogues by Altmann and coworkers

The first total synthesis of nafuredin B (237) was accomplished by Goswami and co-workers (Scheme 27) ${ }^{112}$ and was based on an elongation sequence of one HWE reaction and two Julia-Kocienski olefinations. Commercially available prenol was converted into unsaturated ester $\mathbf{2 2 9}$ using a known procedure. Ester $\mathbf{2 2 9}$ was then reduced with DIBAL-H and oxidized with Dess-Martin periodinane and the intermediate aldehyde was directly subjected to JuliaKocienski olefination with sulfone $\mathbf{2 3 0}$ to obtain the olefin $(E / Z 4: 1)$. The isomers were separated and the $E$-isomer was treated with TBAF to produce primary alcohol 231, which was again oxidized and treated with Grignard reagent to

Separacenes A (242) and B (243) were isolated in 2013 from a marine actinomycete ${ }^{115}$ and contain an unusual tetraene moiety with a diols on both ends. Goswami and Das reported the first convergent stereoselective total synthesis (Scheme 28) shortly afterwards in 2017.29 The synthesis started from D-tartaric acid which was transformed to unsaturated ester 238 (see Table 1, Entry 14). A deprotection/protection and reduction/oxidation sequence yields TBSOTf-protected aldehyde $\mathbf{2 3 9}$. They screened several conditions for the HWE reaction of aldehyde 239 and ketophosphonate 240, such as LiCl, DIPEA, THF (0\%, 24 h); $\mathrm{LiCl}$, $\operatorname{DBU}, \operatorname{THF}(0 \%, 24 \mathrm{~h}) ; \mathrm{Cs}_{2} \mathrm{CO}_{3}, \operatorname{MeCN}(60 \%, 5.5: 1 \mathrm{dr}, 12 \mathrm{~h})$, and were finally able to react $\mathbf{2 3 9}$ with $\mathbf{2 4 0}$ in the presence of 
<smiles>C=CC(=O)C(C=CC=CC=CC(=O)OC)OC(C)(C)C</smiles>

1. CSA, EtOH, $87 \%$

2. TBSOTf, 2,6-lutidine, DCM, 95\%

3. DIBAL-H, DCM, $95 \%$

238

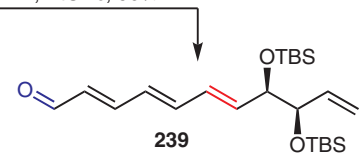

Scheme 28 Total synthesis of separacenes A and B by Goswami and Das

$\mathrm{Ba}(\mathrm{OH})_{2}$ to yield elongated ketone $241(80 \%, 5.5: 1 \mathrm{dr}, 12 \mathrm{~h})$. They obtained 242 and 243 by stereoselective reduction of ketone 241 with the Corey-Bakshi-Shibata reagent $R$-CBS and $S$-CBS, respectively, and global deprotection with TBAF.

The asymmetric total synthesis of (-)-neooxazolomycin (7) (Scheme 29) reported by Kim and co-workers is the final example. ${ }^{25}$ The structurally complex natural product consists of a unique lactam-lactone structure and an unsaturated polyketide-based sidechain that exhibits potent bio-

logical activities. ${ }^{116}$ The key substrate 244 was obtained from D-serine in 16 steps and reacted with dimethyl lithiomethylphosphonate to give phosphonate $\mathbf{2 4 6}$ in $82 \%$ yield. Further modifications yielded dioxasilinane-protected phosphonate 34, ${ }^{117}$ which was then reacted with aldehyde 248 in a temperature-sensitive $\mathrm{Ba}(\mathrm{OH})_{2}$-mediated HWE reaction to afford the partially deprotected and elongated 35 in 75\%. Ketone 35 was subsequently reduced to the corresponding alcohol and acetylated to give 249. The second fragment, 250, was synthesized in 13 steps and coupled with 249. This was then treated with $\mathrm{K}_{2} \mathrm{CO}_{3}$ and $\mathrm{MeOH}$ to produce globally deprotected (+)-neooxazolomycin (7).

\subsection{HWE-Mediated Coupling of Larger Building Blocks}

The intramolecular HWE reaction, where one building block contains a phosphonate moiety and the other has an aldehyde or ketone, has found immediate application in synthetic chemistry and natural product synthesis. Here, we give four recent examples.

Siladenoserinol A (15) was isolated in 2013 from a tunicate collected in Indonesia, ${ }^{118}$ and found to contain a 6,8-dioxabicyclo[3.2.1]octane skeleton with two long chains that each contain a sulfamated serinol or glycerophosphocholine moiety. Doi and co-workers reported the first total synthesis of siladenoserinol A (15) in 2018 (Scheme 30). ${ }^{119}$ Their synthetic strategy started with commercially available D-malic acid, which was converted into aldehyde $\mathbf{2 5 1}$ in 21 steps. The glycerophosphocholine moiety was intro-

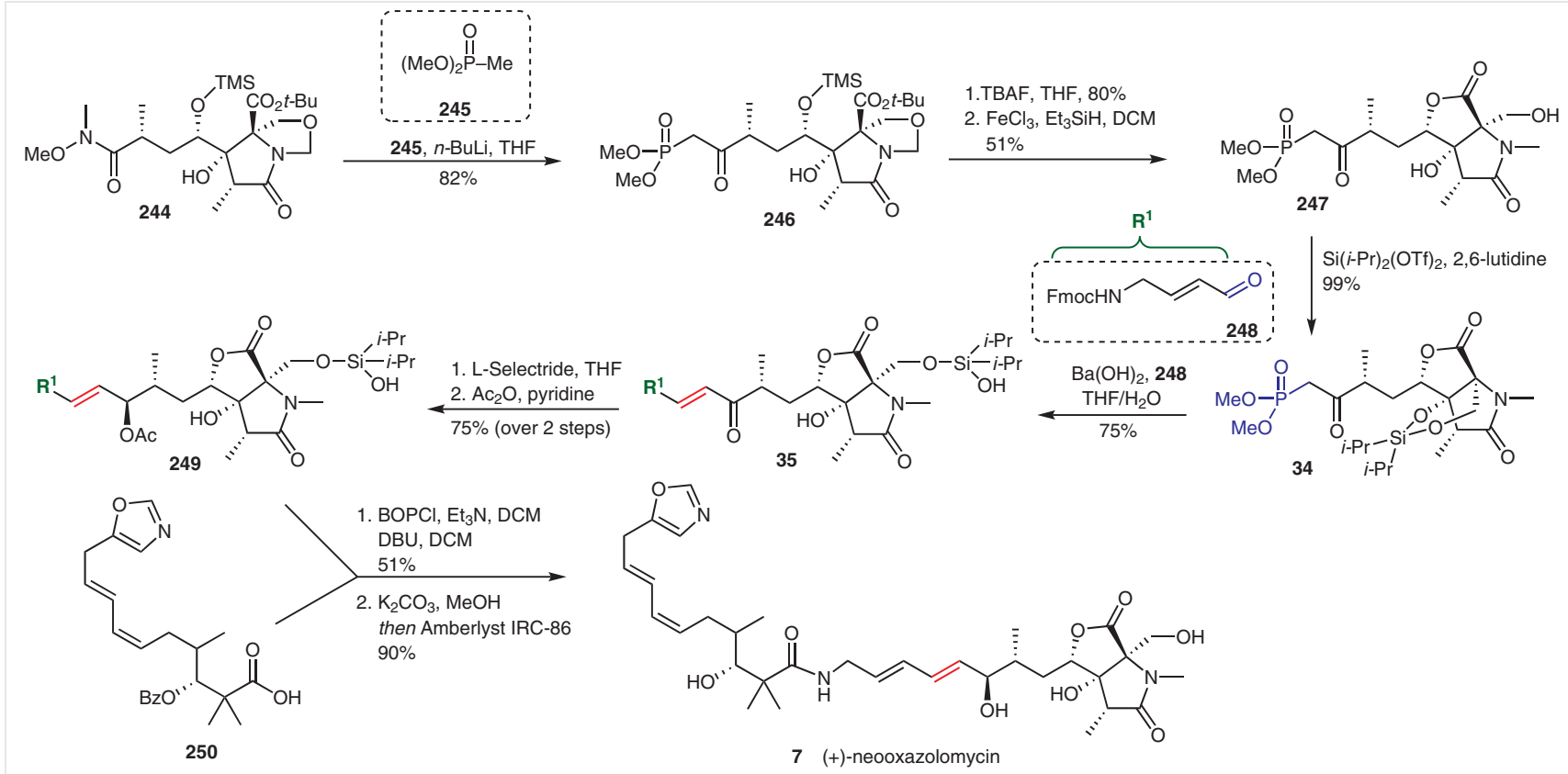

Scheme 29 Total synthesis of (+)-neooxazolomycin accomplished by Kim and co-workers 
duced by an HWE reaction using the previously prepared phosphonate 252 yielding the unsaturated ester 253 in 64\% yield. The Boc group was removed with $\mathrm{HCl}$ and sulfamate formation finished the synthesis of siladenoserinol A (15).

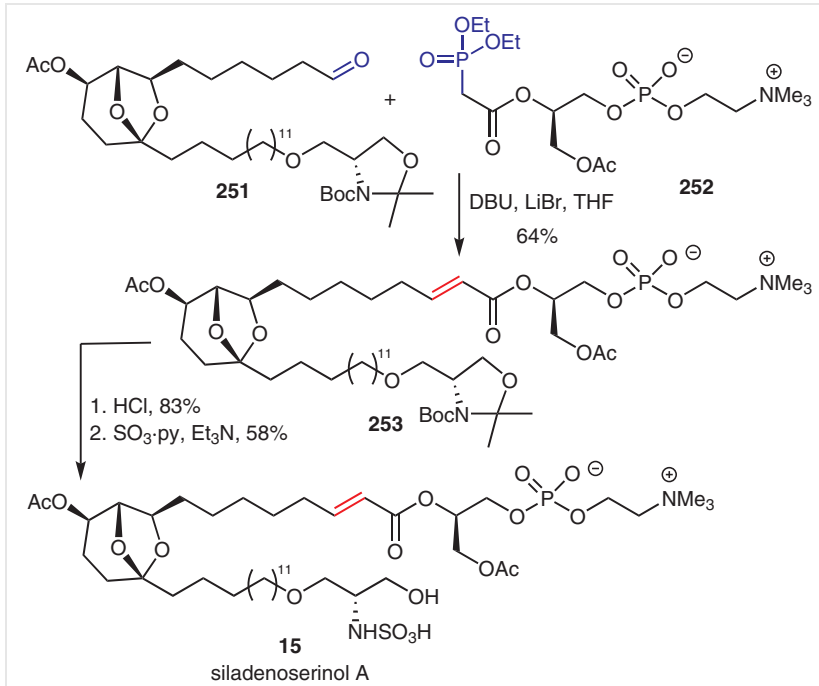

Scheme 30 Total synthesis of siladenoserinol A 15 by Doi and coworkers

Tong, Qian, and co-workers described a second asymmetric synthesis of $\mathbf{1 5}$ in 2019 (see Table 1, formation of 19). ${ }^{17}$ They also applied an HWE reaction for the construction of the $\alpha, \beta$-unsaturated ester moiety and included the synthesis of siladenoserinol $\mathrm{H}$, which is a structural analogue, to test for antibacterial activity of this compound class. ${ }^{120}$

Rhizoxin is a natural product produced by species of the bacterial genus Burkholderia. ${ }^{121}$ It was isolated in 1984 and showed high in vitro cytotoxicity and in vivo antitumor activity. ${ }^{122}$ Fürstner and co-workers presented their own synthetic effort in 2019 that extended earlier studies and resulted in a different modern strategy (Scheme 31). ${ }^{123}$ The synthesis was based on intermolecular HWE olefination for coupling 254 and 255 followed by macrocyclization to form a 16-membered ring through ring-closing alkyne metathesis.

Their synthesis started from commercially available $(R)$ oct-1-en-3-ol in its optically pure form, which was converted into substrate $\mathbf{2 5 4}$ in 14 steps. The second segment $\mathbf{2 5 5}$ was prepared from crotyl alcohol in 11 steps. A straightforward HWE reaction between phosphonate 254 and aldehyde $\mathbf{2 5 5}$ in the presence of $\mathrm{LiCl}$ and DBU was performed to couple both segments and afforded cyclization precursor 256 in 86\% yield. Ring-closing alkyne metathesis was followed by TBAF deprotection of silyl groups and yielded de-

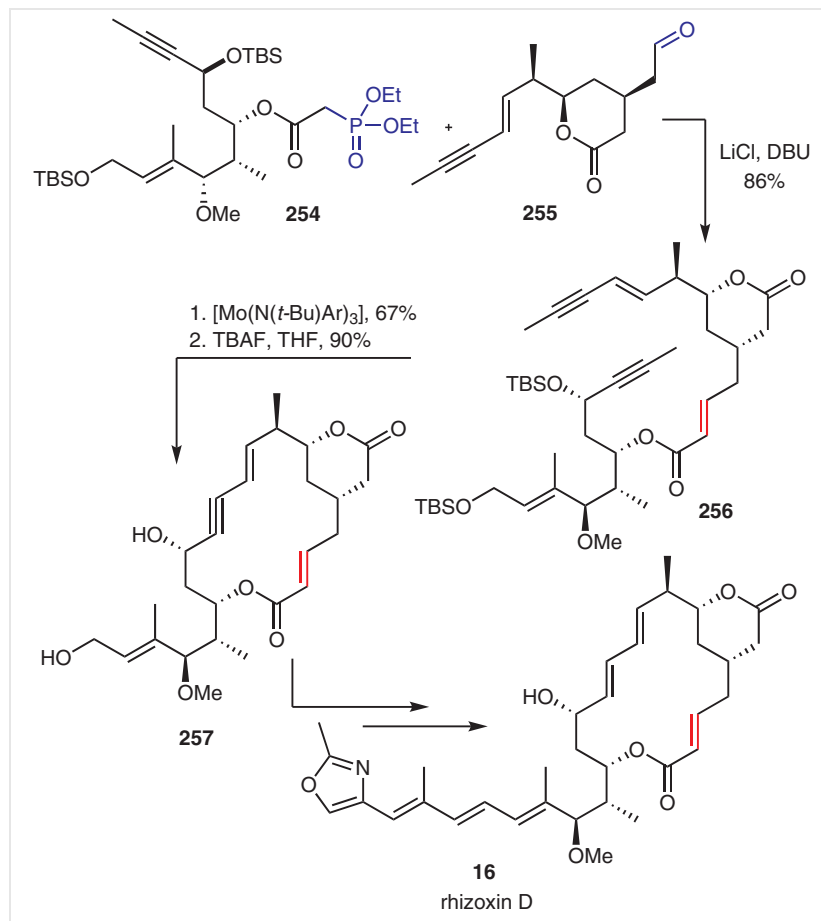

Scheme 31 Total synthesis of rhizoxin D by Fürstner and co-workers

sired macrolactone 257. Next steps such as trans-hydrostannation, $C$-methylation, and other known procedures led to rhizoxin $\mathrm{D}(\mathbf{1 6})$.

Formosalides A (261) and B (262) were isolated in 2009 by $\mathrm{Lu}$ and co-workers from the dinoflagellate Prorocentrum sp. from southern Taiwan. ${ }^{124}$ These macrolides consist of substituted tetrahydropyran (THP), a tetrahydrofuran ring, and a C-14 linear unsaturated chain containing four cisdouble bonds. ${ }^{125}$ Both compounds exhibited good cytotoxic activity against human T-cell, acute leukemia cells, and human colon adenocarcinoma cells and were thus selected for total synthesis.

Mohapatra and co-workers reported a simple and efficient synthesis of the $\mathrm{C} 1-\mathrm{C} 16$ fragment of the proposed structure of formosalide B (262) (Scheme 32). ${ }^{21}$ The synthesis started from commercially available materials and was completed in 9 steps. Aldehyde $\mathbf{2 5 8}$ was prepared from pentane-1,5-diol in 5 steps. Both building blocks were then coupled using an HWE reaction in the presence of $\mathrm{LiCl}$ and DIPEA in acetonitrile to furnish the E-isomer enone $\mathbf{2 7}$ in 91\% yield. Olefin 27 underwent dihydroxylation using a Sharpless ligand to give diol 259 ( $\mathrm{dr}$ 9:1). Finally, 259 was subjected to acid-mediated ketalization to form the THP ring 260 and complete the fully functional $\mathrm{C} 1-\mathrm{C} 16$ fragment of formosalide B (262). 


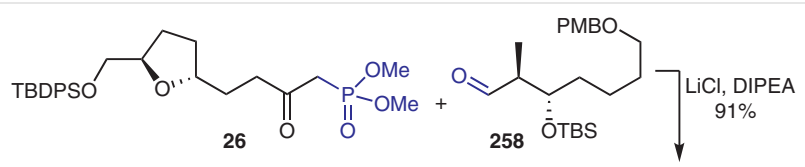
(DHQD) $)_{2} \mathrm{PHAL}, \mathrm{K}_{3} \mathrm{Fe}(\mathrm{CN})_{6}$ $\mathrm{K}_{2} \mathrm{CO}_{3}, \mathrm{MeSO}_{2} \mathrm{NH}_{2}$ $\sqrt{80 \%}$ TBDPSO<smiles>CCC(O)CO</smiles>

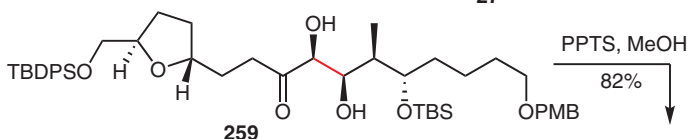

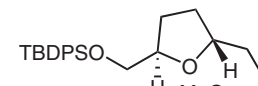

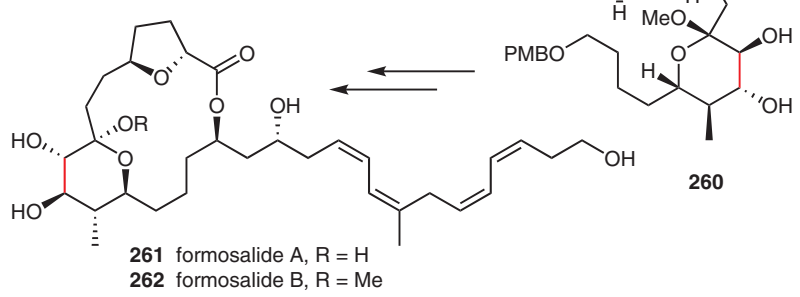

Scheme 32 Total synthesis of the $\mathrm{C} 1-\mathrm{C} 16$ fragment of formosalides by Mohapatra and co-workers

Exiguolide (271) was isolated in 2006 from a marine sponge Geodia exigua Thiele by Ohta, Ikegami, and co-workers. ${ }^{126}$ It contains a unique 20 -membered macrolide core and two tetrahydropyran rings and was shown to have inhibitory activity against human lung cell carcinoma, human lung adenocarcinoma cells, pancreatic cancer, and breast cancer cells. ${ }^{127}$ Exiguolide (271) has been a captivating target for synthesis due to its interesting structure and remarkable biological properties. The first total synthesis of it was accomplished in 2010 by Sasaki and Fuwa. ${ }^{128}$ Several synthetic strategies have since been developed and described. ${ }^{129}$ In 2020, Ishihara and co-workers reported an asymmetric total synthesis of 271 (Scheme 33). ${ }^{130}$ The first building block, 263, was prepared in 8 steps and the THPbased fragment, 264, was prepared from propane-1,3-diol in 7 steps. Phosphonate $\mathbf{2 6 3}$ and aldehyde $\mathbf{2 6 4}$ were then subjected to an HWE reaction using $\mathrm{NaH}$ to give enone $\mathbf{2 6 5}$ in a $68 \%$ yield. This was then reacted with Stryke's reagent to provide a saturated compound. ${ }^{131}$ Cleavage of MOM and Bn groups by treatment with trimethylsilyl iodide was accomplished, which was followed by silane reduction that yielded bis(tetrahydropyran) $\mathbf{2 6 6}$ as single isomer. ${ }^{132}$ Saponification, macrolactonization, removal of the TBDPS group, and subsequent oxidation of the secondary alcohol to the corresponding aldehyde yielded compound 267. An asymmetric HWE reaction based on Fuji's method was employed to convert aldehyde $\mathbf{2 6 7}$ with chiral phosphonate
268 in the presence of NaHMDS to obtain 269 in a quantitative yield (Z/E 3.6:1). Hydrostannylation and Stille coupling produced pure (-)-exiguolide $\mathbf{2 7 1}$ ( $Z$-isomer).

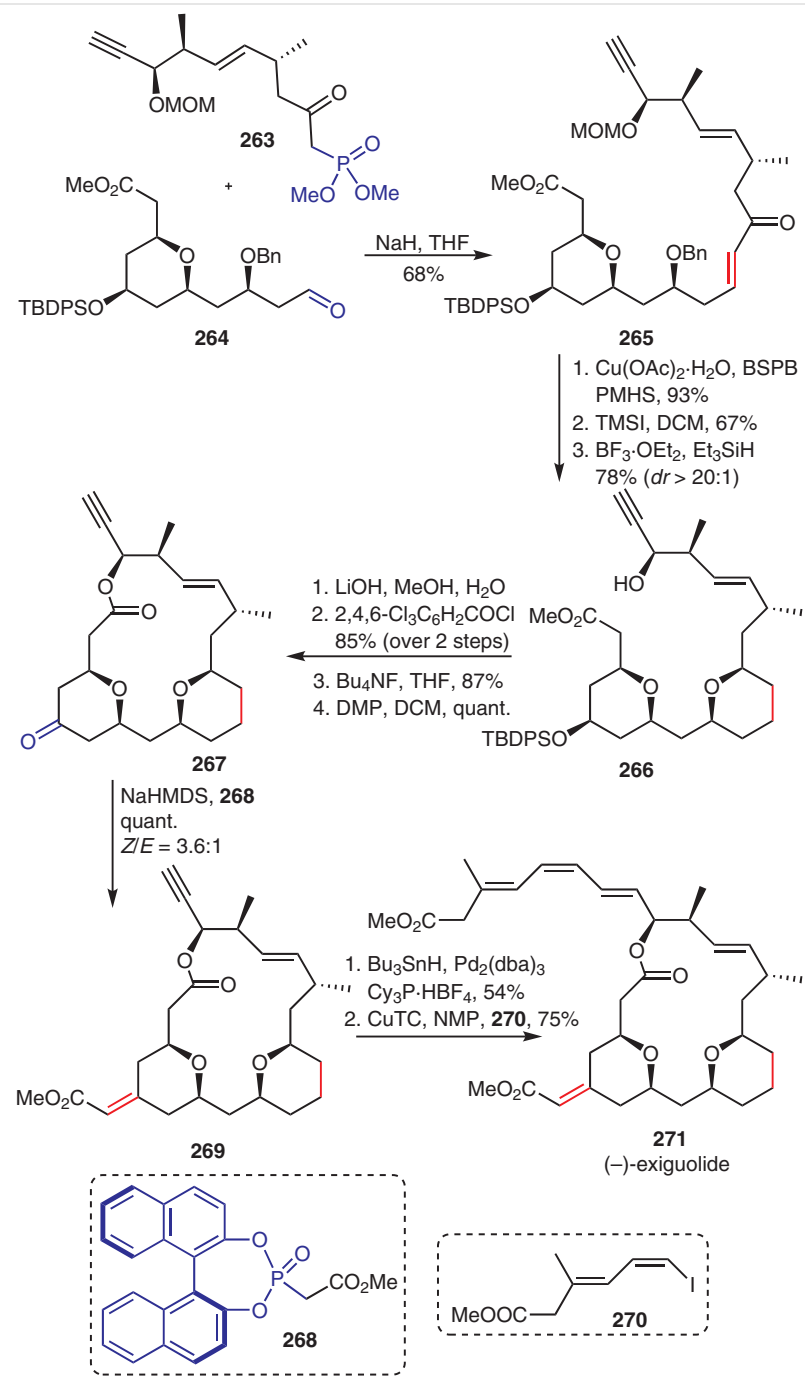

Scheme 33 Total synthesis of (-)-exiguolide by Ishihara and co-workers

\subsection{Miscellaneous}

$\mathrm{Xu}$ and co-workers described the first enantioselective total synthesis of dapholdhamine B (276) in 2019, an alkaloid with a rare aza-adamantane core skeleton (Scheme 34A). ${ }^{133}$ The critical homologation of the key building block 272 was achieved via an HWE reaction with $\mathbf{2 7 3}$ in the presence of $\mathrm{NaH}$ to give intermediate 274, which then underwent a one-pot acidic hydrolysis to obtain thioester 275. This was followed by basic hydrolysis to obtain dapholdhamine B (276) (21 steps). 

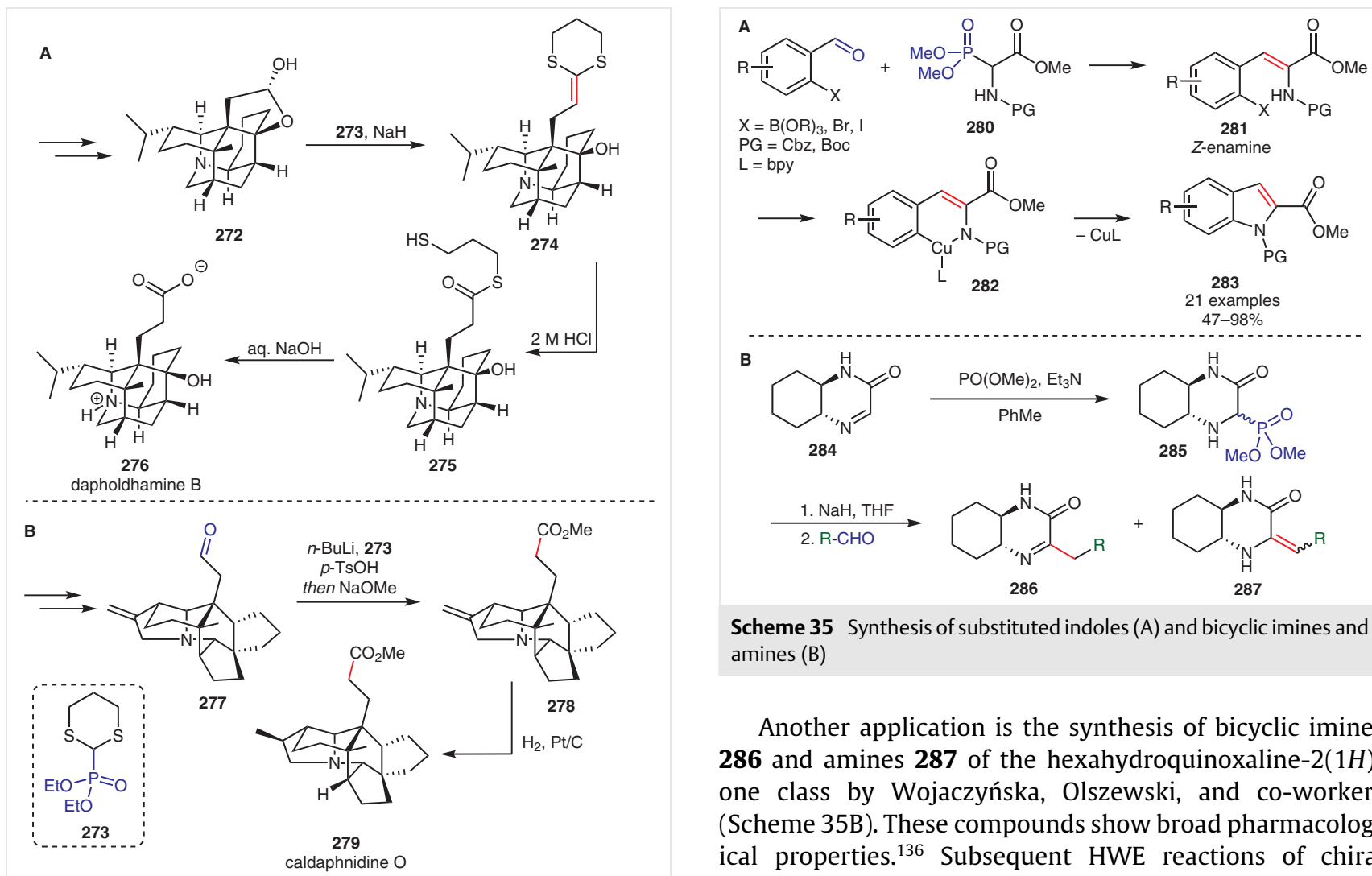

Scheme 34 Total synthesis of dapholdhamine B and caldaphnidine $O$ by $\mathrm{Xu}$ and co-workers

$\mathrm{Xu}$ and co-workers also reported the total synthesis of alkaloid (-)-caldaphnidine $O(\mathbf{2 7 9})$ in 22 steps from cyclohexane-1,3-dione (Scheme 34B). ${ }^{134}$ After the synthesis of aldehyde 277, they employed an HWE reaction with thioketal phosphonate $\mathbf{2 7 3}$ and $n$-BuLi followed by acidic and basic workup to produce methyl ester 278. After diastereoselective hydrogenation of the alkene motif they obtained (-)-caldaphnidine $\mathrm{O}(\mathbf{2 7 9})$.

In a second example, Lim and Choi employed an HWE reaction for synthesis of indoles and azaindoles (Scheme 35A). ${ }^{135}$ In detail, reaction of commercially available $\mathrm{N}$-Cbzprotected phosphonoglycine trimethyl ester $\mathbf{2 8 0}$ and substituted 2-bromobenzaldehydes afforded enamines 281, which were converted into indole $\mathbf{2 8 3}$ via Cu-catalyzed cyclization. This method was also envisaged for the synthesis of thiophene- and benzothiophene-linked pyrroles, which makes it a versatile tool in drug discovery.

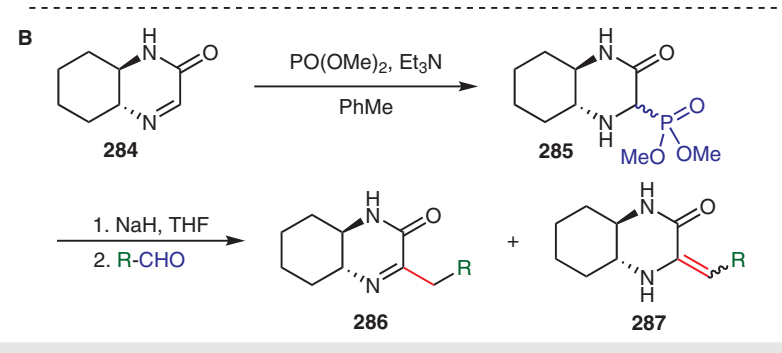

Scheme 35 Synthesis of substituted indoles (A) and bicyclic imines and amines (B)

Another application is the synthesis of bicyclic imines 286 and amines 287 of the hexahydroquinoxaline- $2(1 H)$ one class by Wojaczyńska, Olszewski, and co-workers (Scheme 35B). These compounds show broad pharmacological properties. ${ }^{136}$ Subsequent HWE reactions of chiral phosphonate $\mathbf{2 8 5}$ with different aldehydes in the presence of $\mathrm{NaH}$ resulted in a tautomeric mixture of imine $\mathbf{2 8 6}$ and enamine 287, in favor of the imine form. Additional reduction of the imine or enamine with $\mathrm{NaBH}_{4}$ led to bicyclic amines.

\section{Summary and Outlook}

In recent decades, the HWE reaction has been an active area for applications to natural product synthesis. To solve increasingly challenging synthetic problems the required phosphonate reagents have been diversified from simple phosphonates to highly activated, branched, and modified phosphonate reagents. Here, we have summarized representative examples of functionalized reagents used in natural product synthesis reported in 2015-2020. Our comprehensive review will support future synthetic approaches and serve as guideline to find the best HWE conditions for the most complicated natural products.

\section{Conflict of Interest}

The authors declare no conflict of interest. 


\section{Funding Information}

We greatly acknowledge funding from the European Research Council (ERC) under the European Union's Horizon 2020 research and innovation program (Project: 802736 MORPHEUS) and Boehringer Ingelheim Stiftung (Exploration Grant Engina).

\section{References}

(1) Wittig, G.; Haag, W. Chem. Ber. 1955, 88, 1654.

(2) (a) Maryanoff, B. E.; Reitz, A. B. Chem. Rev. 1989, 89, 863. (b) Byrne, P. A.; Gilheany, D. G. Chem. Soc. Rev. 2013, 42, 6670. (c) Rocha, D. H.; Pinto, D. C.; Silva, A. M. Eur. J. Org. Chem. 2018, 2018, 2443. (d) Heravi, M. M.; Ghanbarian, M.; Zadsirjan, V.; Jani, A. B. Monatsh. Chem. 2019, 150, 1365.

(3) Horner, L.; Hoffmann, H.; Wippel, H. G. Chem. Ber. 1958, 91, 61.

(4) Wadsworth, W. S.; Emmons, W. D. J. Am. Chem. Soc. 1961, 83, 1733.

(5) Still, W. C.; Gennari, C. Tetrahedron Lett. 1983, 24, 4405.

(6) Janicki, I.; Kiełbasiński, P. Adv. Synth. Catal. 2020, 362, 2552.

(7) (a) Ando, K. Tetrahedron Lett. 1995, 36, 4105. (b) Ando, K. J. Org. Chem. 1997, 62, 1934.

(8) Blanchette, M. A.; Choy, W.; Davis, J. T.; Essenfeld, A. P.; Masamune, S.; Roush, W. R.; Sakai, T. Tetrahedron Lett. 1984, 25, 2183.

(9) Rathke, M. W.; Nowak, M. J. Org. Chem. 1985, 50, 2624.

(10) Pascariu, A.; Ilia, G.; Bora, A.; Bora, A.; Iliescu, S.; Popa, A.; Dehelean, G.; Pacureanu, L. Cent. Eur. J. Chem. 2003, 1, 491.

(11) (a) Teichert, A.; Jantos, K.; Harms, K.; Studer, A. Org. Lett. 2004, 6, 3477. (b) Schauer, D. J.; Helquist, P. Synthesis 2006, 3654.

(12) (a) Sano, S.; Yokoyama, K.; Teranishi, R.; Shiro, M.; Nagao, Y. Tetrahedron Lett. 2002, 43, 281. (b) Sano, S.; Abe, S.; Azetsu, T.; Nakao, M.; Shiro, M.; Nagao, Y. Lett. Org. Chem. 2006, 3, 798.

(13) (a) Julia, M.; Paris, J.-M. Tetrahedron Lett. 1973, 14, 4833. (b) Blakemore, P. R.; Sephton, S. M.; Ciganek, E. Org. React. (N. Y.) 2018, 95, 1-422.

(14) (a) Peterson, D. J. J. Org. Chem. 1968, 33, 780. (b) van Staden, L. F.; Gravestock, D.; Ager, D. J. Chem. Soc. Rev. 2002, 31, 195.

(15) (a) Mikołajczyk, M.; Midura, W. H.; Mohamed Ewas, A. M.; Perlikowska, W.; Mikina, M.; Jankowiak, A. Phosphorus, Sulfur Silicon Relat. Elem. 2008, 183, 313. (b) Bisceglia, J. A.; Orelli, L. R. Curr. Org. Chem. 2012, 16, 2206. (c) Bisceglia, J. A.; Orelli, L. R. Curr. Org. Chem. 2015, 19, 744. (d) Kobayashi, K.; Tanaka, K.; Kogen, H. Tetrahedron Lett. 2018, 59, 568.

(16) Nicolaou, K.; Das, D.; Lu, Y.; Rout, S.; Pitsinos, E. N.; Lyssikatos, J.; Schammel, A.; Sandoval, J.; Hammond, M.; Aujay, M. J. Am. Chem. Soc. 2020, 142, 2549.

(17) Márquez-Cadena, M. A.; Ren, J.; Ye, W.; Qian, P.; Tong, R. Org. Lett. 2019, 21, 9704.

(18) Shimoda, K.; Yamaoka, Y.; Yoo, D.; Yamada, K.-i.; Takikawa, H.; Takasu, K. J. Org. Chem. 2019, 84, 11014.

(19) Scheeff, S.; Menche, D. Org. Lett. 2019, 21, 271.

(20) Lee, S.; Kang, G.; Chung, G.; Kim, D.; Lee, H.-Y.; Han, S. Angew. Chem. Int. Ed. 2020, 59, 6894.

(21) Gajula, S.; Reddy, A. V. V.; Reddy, D. P.; Yadav, J. S.; Mohapatra, D. K. ACS Omega 2020, 5, 10217.

(22) AnkiReddy, P.; AnkiReddy, S.; Gowravaram, S. Org. Biomol. Chem. 2018, 16, 4191.

(23) Boeckman, R. K. Jr.; Wang, H.; Rugg, K. W.; Genung, N. E.; Chen, K.; Ryder, T. R. Org. Lett. 2016, 18, 6136.

(24) Raji Reddy, C.; Mohammed, S. Z.; Gaddam, K.; Prapurna, Y. L. Synth. Commun. 2019, 49, 1153.
(25) Kim, J. H.; Kim, I.; Song, Y.; Kim, M. J.; Kim, S. Angew. Chem. Int. Ed. 2019, 58, 11018.

(26) Boyko, Y. D.; Huck, C. J.; Sarlah, D. J. Am. Chem. Soc. 2019, 141, 14131.

(27) Poock, C.; Kalesse, M. Org. Lett. 2017, 19, 4536.

(28) Bruckner, S.; Weise, M.; Schobert, R. J. Org. Chem. 2018, 83, 10805.

(29) Das, S.; Goswami, R. K. Org. Biomol. Chem. 2017, 15, 4842.

(30) Sakai, T.; Fukuta, A.; Nakamura, K.; Nakano, M.; Mori, Y. J. Org. Chem. 2016, 81, 3799.

(31) Brumley, D. A.; Gunasekera, S. P.; Chen, Q.-Y.; Paul, V. J.; Luesch, H. Org. Lett. 2020, 22, 4235.

(32) Dash, U.; Sengupta, S.; Sim, T. Eur. J. Org. Chem. 2015, 2015, 3963.

(33) Yang, L.; Lin, Z.; Shao, S.; Zhao, Q.; Hong, R. Angew. Chem. Int. Ed. 2018, 57, 16200.

(34) Long, X.; Ding, Y.; Deng, J. Angew. Chem. Int. Ed. 2018, 57, 14221.

(35) Nicolaou, K.; Shelke, Y. G.; Dherange, B. D.; Kempema, A.; Lin, B.; Gu, C.; Sandoval, J.; Hammond, M.; Aujay, M.; Gavrilyuk, J.J. Org. Chem. 2020, 85, 2865.

(36) Saha, D.; Guchhait, S.; Goswami, R. K. Org. Lett. 2020, 22, 745.

(37) Pakhare, D.; Kusurkar, R. New J. Chem. 2016, 40, 5428.

(38) Chinthakindi, P. K.; Nandi, G. C.; Govender, T.; Kruger, H. G.; Naicker, T.; Arvidsson, P. I. Synlett 2016, 27, 1423.

(39) (a) Stork, G.; Nakamura, E. J. Org. Chem. 1979, 44, 4010. (b) Nangia, A.; Prasuna, G.; Bheema Rao, P. Tetrahedron Lett. 1994, 35, 3755.

(40) Stork, G.; Matthews, R. J. Chem. Soc. D 1970, 445.

(41) (a) Nicolaou, K. C.; Seitz, S. P.; Pavia, M. R.; Petasis, N. A. J. Org. Chem. 1979, 44, 4011. (b) Still, W. C.; Novack, V.J. Am. Chem. Soc. 1984, 106, 1148. (c) Still, W. C.; Gennari, C.; Noguez, J. A.; Pearson, D. A. J. Am. Chem. Soc. 1984, 106, 260. (d) Morin-Fox, M. L.; Lipton, M. A. Tetrahedron Lett. 1993, 34, 7899.

(42) Gourves, J.-P.; Couthon, H.; Sturtz, G. Eur. J. Org. Chem. 1999, 1999, 3489.

(43) (a) Meyers, A. I.; Comins, D. L.; Roland, D. M.; Henning, R.; Shimizu, K. J. Am. Chem. Soc. 1979, 101, 7104. (b) Tius, M. A.; Fauq, A. H. J. Am. Chem. Soc. 1986, 108, 1035. (c) Tius, M. A.; Fauq, A. J. Am. Chem. Soc. 1986, 108, 6389. (d) Marshall, J. A.; DeHoff, B. S. Tetrahedron 1987, 43, 4849. (e) Smith, A. B.; Rano, T. A.; Chida, N.; Sulikowski, G. A.; Wood, J. L. J. Am. Chem. Soc. 1992, 114, 8008. (f) Zhang, J.; Xu, X. Tetrahedron Lett. 2000, 41, 941.

(44) (a) Wessjohann, L. A.; Ruijter, E.; Garcia-Rivera, D.; Brandt, W. Mol. Diversity 2005, 9, 171. (b) Swinney, D. C.; Anthony, J. Nat. Rev. Drug Discovery 2011, 10, 507. (c) Madsen, C. M.; Clausen, M. H. Eur. J. Org. Chem. 2011, 2011, 3107. (d) Mallinson, J.; Collins, I. Future Med. Chem. 2012, 4, 1409. (e) Yu, X.; Sun, D. Molecules 2013, 18, 6230. (f) Giordanetto, F.; Kihlberg, J. J. Med. Chem. 2014, 57, 278. (g) Newman, D. J.; Cragg, G. M. Bioactive Macrocycles from Nature, In Macrocycles in Drug Discovery; Chap. 1; RSC: Cambridge, 2015, 1. (h) Mortensen, K. T.; Osberger, T. J.; King, T. A.; Sore, H. F.; Spring, D. R. Chem. Rev. 2019, 119, 10288.

(45) Scherlach, K.; Boettger, D.; Remme, N.; Hertweck, C. Nat. Prod. Rep. 2010, 27, 869.

(46) (a) Schofield, J. Nat. New Biol. 1971, 234, 215. (b) Turner, W. B.; Carter, S. B. Biochem. J. 1972, 127, 1P. (c) Crivello, J. F.; Jefcoate, C. R. Biochim. Biophys. Acta, Gen. Subj. 1978, 542, 315. (d) Hu, Y.; Zhang, W.; Zhang, P.; Ruan, W.; Zhu, X. J. Agric. Food Chem. 2013, 61, 41. (e) Hua, C.; Yang, Y.; Sun, L.; Dou, H.; Tan, R.; Hou, Y. Immunobiology 2013, 218, 292.

(47) Stork, G.; Nakamura, E. J. Am. Chem. Soc. 1983, 105, 5510. 
(48) Stork, G.; Nakahara, Y.; Nakahara, Y.; Greenlee, W. J. Am. Chem. Soc. 1978, 100, 7775.

(49) Thomas, E. J.; Whitehead, J. W. F. J. Chem. Soc., Chem. Commun. 1986, 727.

(50) Merifield, E.; Thomas, E. J. J. Chem. Soc., Perkin Trans. 1 1999, 3269.

(51) Thomas, E. J.; Willis, M. Org. Biomol. Chem. 2014, 12, 7537.

(52) Trost, B. M.; Ohmori, M.; Boyd, S. A.; Okawara, H.; Brickner, S. J. J. Am. Chem. Soc. 1989, 111, 8281.

(53) Reyes, J. R.; Winter, N.; Spessert, L.; Trauner, D. Angew. Chem. Int. Ed. 2018, 57, 15587.

(54) Draskovits, M.; Stanetty, C.; Baxendale, I. R.; Mihovilovic, M. D. J. Org. Chem. 2018, 83, 2647.

(55) Enders, D.; Geibel, G.; Osborne, S. Chem. Eur. J. 2000, 6, 1302.

(56) Zaghouani, M.; Kunz, C.; Guédon, L.; Blanchard, F.; Nay, B. Chem. Eur. J. 2016, 22, 15257.

(57) Forsyth, C. J.; Ahmed, F.; Cink, R. D.; Lee, C. S. J. Am. Chem. Soc. 1998, $120,5597$.

(58) Haidle, A. M.; Myers, A. G. Proc. Natl. Acad. Sci. U.S.A. 2004, 101, 12048.

(59) Larsen, B. J.; Sun, Z.; Nagorny, P. Org. Lett. 2013, 15, 2998.

(60) (a) Zhanel, G. G.; Dueck, M.; Hoban, D. J.; Vercaigne, L. M.; Embil, J. M.; Gin, A. S.; Karlowsky, J. A. Drugs 2001, 61, 443. (b) Zhanel, G. G.; Walters, M.; Noreddin, A.; Vercaigne, L. M.; Wierzbowski, A.; Embil, J. M.; Gin, A. S.; Douthwaite, S.; Hoban, D. J. Drugs 2002, 62, 1771. (c) Cui, W.; Ma, S. Mini-Rev. Med. Chem. 2011, 11, 1009. (d) Arsic, B.; Barber, J.; Čikoš, A.; Mladenovic, M.; Stankovic, N.; Novak, P. Int. J. Antimicrob. Agents 2018, 51, 283.

(61) Liu, S.; Dai, H.; Makhloufi, G.; Heering, C.; Janiak, C.; Hartmann, R.; Mándi, A.; Kurtán, T.; Müller, W. E.; Kassack, M. U.; Lin, W.; Liu, Z.; Proksch, P. J. Nat. Prod. 2016, 79, 2332.

(62) Paul, D.; Saha, S.; Goswami, R. K. Org. Lett. 2018, 20, 4606.

(63) Dias, L. C.; de Lucca, E. C. J. Org. Chem. 2017, 82, 3019.

(64) (a) Takai, K.; Nitta, K.; Utimoto, K. J. Am. Chem. Soc. 1986, 108, 7408. (b) Okazoe, T.; Takai, K.; Utimoto, K. J. Am. Chem. Soc. 1987, 109, 51 .

(65) (a) Inanaga, J.; Hirata, K.; Saeki, H.; Katsuki, T.; Yamaguchi, M. Bull. Chem. Soc. Jpn. 1979, 52, 1989. (b) Kawanami, Y.; Dainobu, Y.; Inanaga, J.; Katsuki, T.; Yamaguchi, M. Bull. Chem. Soc. Jpn. 1981, 54, 943

(66) Clarke, A. K.; Unsworth, W. P. Chem. Sci. 2020, 11, 2876.

(67) Hubert, J. G.; Furkert, D. P.; Brimble, M. A. J. Org. Chem. 2015, 80, 2231.

(68) (a) Wang, W.; Mun, B.; Lee, Y.; Venkat Reddy, M.; Park, Y.; Lee, J.; Kim, H.; Hahn, D.; Chin, J.; Ekins, M.; Nam, S.-J.; Kang, H. J. Nat. Prod. 2013, 76, 170. (b) Hubert, J. G.; Furkert, D. P.; Brimble, M. A. J. Org. Chem. 2015, 80, 2715.

(69) Saya, J. M.; Vos, K.; Kleinnijenhuis, R. A.; van Maarseveen, J. H.; Ingemann, S.; Hiemstra, H. Org. Lett. 2015, 17, 3892.

(70) (a) Jeon, S.; Han, S. J. Am. Chem. Soc. 2017, 139, 6302. (b) Wang, Y.; Chen, B.; He, X.; Gui, J. J. Am. Chem. Soc. 2020, 142, 5007.

(71) (a) Chirkin, E.; Atkatlian, W.; Porée, F.-H. The Securinega Alkaloids, In The Alkaloids: Chemistry and Biology, Vol. 74, Chap. 1; Knölker, H.-J., Ed.; Academic Press: San Diego, 2015, 1. (b) Zhang, H.; Zhang, C.-R.; Han, Y.-S.; Wainberg, M. A.; Yue, J.M. RSC Adv. 2015, 5, 107045. (c) Park, K. J.; Kim, C. S.; Khan, Z.; Oh, J.; Kim, S. Y.; Choi, S. U.; Lee, K. R. J. Nat. Prod. 2019, 82, 1345.

(72) Xie, P.; Huang, Y. Eur. J. Org. Chem. 2013, 28, 6213.
(73) (a) Cimmino, A.; Andolfi, A.; Fondevilla, S.; Abouzeid, M. A.; Rubiales, D.; Evidente, A. J. Agric. Food Chem. 2012, 60, 5273. (b) Yadav, J. S.; Avuluri, S.; Kattela, S. S.; Das, S. Eur. J. Org. Chem. 2013, 2013, 6967. (c) Jangili, P.; Kumar, C. G.; Poornachandra, Y.; Das, B. Synthesis 2015, 47, 653.

(74) Shelke, A. M.; Suryavanshi, G. Tetrahedron: Asymmetry 2016, 27, 142.

(75) Kobayashi, J.-i.; Watanabe, D.; Kawasaki, N.; Tsuda, M. J. J. Org. Chem. 1997, 62, 9236.

(76) (a) Sakai, R.; Higa, T.; Jefford, C. W.; Bernardinelli, G. J. J. Am. Chem. Soc. 1986, 108, 6404. (b) Ashok, P.; Ganguly, S.; Murugesan, S. Drug Discovery Today 2014, 19, 1781. (c) Ashok, P.; Lathiya, H.; Murugesan, S. Eur. J. Med. Chem. 2015, 97, 928. (d) Kondo, K.; Shigemori, H.; Kikuchi, Y.; Ishibashi, M.; Sasaki, T.; Kobayashi, J. J. Org. Chem. 1992, 57, 2480.

(77) Hovey, M. T.; Cohen, D. T.; Walden, D. M.; Cheong, P. H.-Y.; Scheidt, K. A. Angew. Chem. Int. Ed. 2017, 56, 9864.

(78) (a) Lumyong, K.; Kongkathip, B.; Chuanopparat, N.; Kongkathip, N. Tetrahedron 2019, 75, 533. (b) Fitch, R. W.; Garraffo, H. M.; Spande, T. F.; Yeh, H. J.; Daly, J. W. J. Nat. Prod. 2003, 66, 1345.

(79) (a) Raluy, E.; Pàmies, O.; Dieguez, M. Adv. Synth. Catal. 2009, 351, 1648. (b) Kongkathip, B.; Akkarasamiyo, S.; Kongkathip, N. Tetrahedron 2015, 71, 2393.

(80) Fulton, M. G.; Bertron, J. L.; Reed, C. W.; Lindsley, C. W. J. Org. Chem. 2019, 84, 12187.

(81) Zhang, D.; Tao, X.; Chen, R.; Liu, J.; Li, L.; Fang, X.; Yu, L.; Dai, J. Org. Lett. 2015, 17, 4304.

(82) Lücke, D.; Linne, Y.; Hempel, K.; Kalesse, M. Org. Lett. 2018, 20, 4475.

(83) Gao, S.-S.; Li, X.-M.; Du, F.-Y.; Li, C.-S.; Proksch, P.; Wang, B.-G. Mar. Drugs 2011, 9, 59.

(84) Sato, S.; Iwata, F.; Mukai, T.; Yamada, S.; Takeo, J.; Abe, A.; Kawahara, H. J. Org. Chem. 2009, 74, 5502.

(85) Hu, N.; Dong, C.; Zhang, C.; Liang, G. Angew. Chem. Int. Ed. 2019, 58,6659 .

(86) Nicolaou, K.; Wang, Y.; Lu, M.; Mandal, D.; Pattanayak, M. R.; Yu, R.; Shah, A. A.; Chen, J. S.; Zhang, H.; Crawford, J. J. J. Am. Chem. Soc. 2016, 138, 8235.

(87) (a) Ley, S. V.; Baxendale, I. R.; Bream, R. N.; Jackson, P. S.; Leach, A. G.; Longbottom, D. A.; Nesi, M.; Scott, J. S.; Storer, R. I.; Taylor, S. J. J. Chem. Soc., Perkin Trans. 1 2000, 3815. (b) Solinas, A.; Taddei, M. Synthesis 2007, 2409.

(88) Johnson, C. R.; Zhang, B. Tetrahedron Lett. 1995, 36, 9253.

(89) Barrett, A. G. M.; Cramp, S. M.; Roberts, R. S.; Zecri, F. J. Org. Lett. $1999,1,579$.

(90) Nicolaou, K. C.; Pastor, J.; Winssinger, N.; Murphy, F. J. Am. Chem. Soc. 1998, 120, 5132.

(91) Salvino, J. M.; Kiesow, T. J.; Darnbrough, S.; Labaudiniere, R. J. Comb. Chem. 1999, 1, 134.

(92) (a) Wipf, P.; Henninger, T. C. J. Org. Chem. 1997, 62, 1586. (b) Boldi, A. M.; Johnson, C. R.; Eissa, H. O. Tetrahedron Lett. 1999, 40, 619.

(93) (a) Martina, S. L. X.; Taylor, R. J. K. Tetrahedron Lett. 2004, 45, 3279. (b) Ando, K.; Suzuki, Y. Tetrahedron Lett. 2010, 51, 2323.

(94) Jin, Y. Z.; Yasuda, N.; Inanaga, J. Green Chem. 2002, 4, 498.

(95) Popa, A.; Avram, E.; Lisa, G.; Visa, A.; Iliescu, S.; Parvulescu, V.; Ilia, G. Polym. Eng. Sci. 2012, 52, 352.

(96) Roman, D.; Raguž, L.; Keiff, F.; Meyer, F.; Barthels, F.; Schirmeister, T.; Kloss, F.; Beemelmanns, C. Org. Lett. 2020, 22, 3744.

(97) Rischer, M.; Raguž, L.; Guo, H.; Keiff, F.; Diekert, G.; Goris, T.; Beemelmanns, C. ACS Chem. Biol. 2018, 13, 1990.

(98) Fuson, R. C. Chem. Rev. 1935, 16, 1. 
(99) (a) Masuda, T.; Osako, K.; Shimizu, T.; Nakata, T. Org. Lett. 1999, 1, 941. (b) Barth, R.; Mulzer, J. Angew. Chem. Int. Ed. 2007, 46, 5791. (c) Denmark, S. E.; Regens, C. S.; Kobayashi, T. J. Am. Chem. Soc. 2007, 129, 2774. (d) Sirasani, G.; Paul, T.; Andrade, R. B. J. Org. Chem. 2008, 73, 6386.

(100)(a) Fadeyi, O. O.; Lindsley, C. W. Org. Lett. 2009, 11, 3950. (b) Takamura, H.; Kikuchi, S.; Nakamura, Y.; Yamagami, Y.; Kishi, T.; Kadota, I.; Yamamoto, Y. Org. Lett. 2009, 11, 2531. (c) Chakor, N. S.; Musso, L.; Dallavalle, S. J. Org. Chem. 2009, 74, 844. (d) Geerdink, D.; Buter, J.; van Beek, T. A.; Minnaard, A. J. Beilstein J. Org. Chem. 2014, 10, 761.

(101) Schmidt, K.; Riese, U.; Li, Z.; Hamburger, M. J. Nat. Prod. 2003, 66, 378.

(102)Zhang, J.; Meng, L.-L.; Wei, J.-J.; Fan, P.; Liu, S.-S.; Yuan, W.-Y.; Zhao, Y.-X.; Luo, D.-Q. Molecules 2017, 22, 2058.

(103) Loscher, S.; Schobert, R. Chem. Eur. J. 2013, 19, 10619.

(104) Gerstmann, L.; Kalesse, M. Chem. Eur. J. 2016, 22, 11210.

(105) Herrmann, A. T.; Martinez, S. R.; Zakarian, A. Org. Lett. 2011, 13 , 3636.

(106) Gehringer, M.; Mäder, P.; Gersbach, P.; Pfeiffer, B.; Scherr, N.; Dangy, J.-P.; Pluschke, G.; Altmann, K.-H. Org. Lett. 2019, 21, 5853.

(107) Bieri, R.; Scherr, N.; Ruf, M.-T.; Dangy, J.-P.; Gersbach, P.; Gehringer, M.; Altmann, K.-H.; Pluschke, G. ACS Chem. Biol. 2017, 12, 1297.

(108) McKenna, M.; Simmonds, R. E.; High, S. J. Cell Sci. 2016, 129, 1404.

(109) Chany, A.-C.; Veyron-Churlet, R.; Tresse, C.; Mayau, V.; Casarotto, V.; Le Chevalier, F.; Guenin-Macé, L.; Demangel, C.; Blanchard, N. J. Med. Chem. 2014, 57, 7382.

(110) Marion, E.; Song, O.-R.; Christophe, T.; Babonneau, J.; Fenistein, D.; Eyer, J.; Letournel, F.; Henrion, D.; Clere, N.; Paille, V. Cell 2014, 157, 1565.

(111)Zhang, Z.; He, X.; Zhang, G.; Che, Q.; Zhu, T.; Gu, Q.; Li, D. J. Nat. Prod. 2017, 80, 3167.

(112) Mandal, G. H.; Saha, D.; Goswami, R. K. Org. Biomol. Chem. 2020, $18,2346$.

(113) Blakemore, P. R.; Cole, W. J.; Kocienski, P.; Morley, A. Synlett 1998, 26.

(114) Seki, M.; Mori, K. Eur. J. Org. Chem. 2001, 2001, 503.

(115) Bae, M.; Kim, H.; Shin, Y.; Kim, B. Y.; Lee, S. K.; Oh, K.-B.; Shin, J.; Oh, D.-C. Mar. Drugs 2013, 11, 2882.

(116)(a) Angelov, P.; Chau, Y. K. S.; Fryer, P. J.; Moloney, M. G.; Thompson, A. L.; Trippier, P. C. Org. Biomol. Chem. 2012, 10, 3472. (b) Josa-Culleré, L.; Towers, C.; Willenbrock, F.; Macaulay, V. M.; Christensen, K. E.; Moloney, M. G. Org. Biomol. Chem. 2017, 15, 5373.

(117) Onyango, E. O.; Tsurumoto, J.; Imai, N.; Takahashi, K.; Ishihara, J.; Hatakeyama, S. Angew. Chem. Int. Ed. 2007, 46, 6703.
(118) Nakamura, Y.; Kato, H.; Nishikawa, T.; Iwasaki, N.; Suwa, Y.; Rotinsulu, H.; Losung, F.; Maarisit, W.; Mangindaan, R. E. P.; Morioka, H.; Yokosawa, H.; Tsukamoto, S. Org. Lett. 2013, 15, 322.

(119) Yoshida, M.; Saito, K.; Kato, H.; Tsukamoto, S.; Doi, T. Angew. Chem. Int. Ed. 2018, 57, 5147.

(120)(a) Tischer, M.; Pradel, G.; Ohlsen, K.; Holzgrabe, U. ChemMedChem 2012, 7, 22. (b) Petkowski, J. J.; Bains, W.; Seager, S. J. Nat. Prod. 2018, 81, 423.

(121)Scherlach, K.; Partida-Martinez, L. P.; Dahse, H.-M.; Hertweck, C. J. Am. Chem. Soc. 2006, 128, 11529.

(122)(a) Iwasaki, S.; Kobayashi, H.; Furukawa, J.; Namikoshi, M.; Okuda, S.; Sato, Z.; Matsuda, I.; Noda, T. J. Antibiot. 1984, 37, 354. (b) Tsuruo, T.; Oh-hara, T.; Iida, H.; Tsukagoshi, S.; Sato, Z.; Matsuda, I.; Iwasaki, S.; Okuda, S.; Shimizu, F.; Sasagawa, K. Cancer Res. 1986, 46, 381. (c) Takahashi, M.; Iwasaki, S.; Kobayashi, H.; Okuda, S.; Murai, T.; Sato, Y.; Haraguchi-Hiraoka, T.; Nagano, H. J. Antibiot. 1987, 40, 66.

(123) Karier, P.; Ungeheuer, F.; Ahlers, A.; Anderl, F.; Wille, C.; Fürstner, A. Angew. Chem. Int. Ed. 2019, 58, 248.

(124) Lu, C.-K.; Chen, Y.-M.; Wang, S.-H.; Wu, Y.-Y.; Cheng, Y.-M. Tetrahedron Lett. 2009, 50, 1825.

(125) (a) Srinivas, B.; Reddy, D. S.; Mallampudi, N. A.; Mohapatra, D. K. Org. Lett. 2018, 20, 6910. (b) Mallampudi, N. A.; Srinivas, B.; Reddy, J. G.; Mohapatra, D. K. Org. Lett. 2019, 21, 5952.

(126) Ohta, S.; Uy, M. M.; Yanai, M.; Ohta, E.; Hirata, T.; Ikegami, S. Tetrahedron Lett. 2006, 47, 1957.

(127) (a) Crane, E. A.; Zabawa, T. P.; Farmer, R. L.; Scheidt, K. A. Angew. Chem. Int. Ed. 2011, 50, 9112. (b) Fuwa, H.; Suzuki, T.; Kubo, H.; Yamori, T.; Sasaki, M. Chem. Eur. J. 2011, 17, 2678. (c) Fuwa, H.; Mizunuma, K.; Sasaki, M.; Suzuki, T.; Kubo, H. Org. Biomol. Chem. 2013, 11, 3442.

(128) Fuwa, H.; Sasaki, M. Org. Lett. 2010, 12, 584.

(129) (a) Cook, C.; Guinchard, X.; Liron, F.; Roulland, E. Org. Lett. 2010, 12, 744. (b) Reddy, C. R.; Rao, N. N. Tetrahedron Lett. 2010, 51, 5840. (c) Cook, C.; Liron, F.; Guinchard, X.; Roulland, E. J. Org. Chem. 2012, 77, 6728. (d) Zhang, Z.; Xie, H.; Li, H.; Gao, L.; Song, Z. Org. Lett. 2015, 17, 4706. (e) Zhang, Y.; Lu, J.; Li, H.; Sun, X.; Gao, L.; Song, Z. Synlett 2019, 30, 753.

(130) Oka, K.; Fuchi, S.; Komine, K.; Fukuda, H.; Hatakeyama, S.; Ishihara, J. Chem. Eur. J. 2020, 26, 12862.

(131) Baker, B. A.; Bošković, Ž. V.; Lipshutz, B. H. Org. Lett. 2008, 10, 289.

(132) Lewis, M. D.; Cha, J. K.; Kishi, Y. J. Am. Chem. Soc. 1982, 104, 4976.

(133) Guo, L.-D.; Hou, J.; Tu, W.; Zhang, Y.; Zhang, Y.; Chen, L.; Xu, J. J. Am. Chem. Soc. 2019, 141, 11713.

(134) Guo, L.-D.; Hu, J.; Zhang, Y.; Tu, W.; Zhang, Y.; Pu, F.; Xu, J. J. Am. Chem. Soc. 2019, 141, 13043.

(135) Choi, J. H.; Lim, H. J. Org. Biomol. Chem. 2015, 13, 5131.

(136) Iwanejko, J.; Sowiński, M.; Wojaczyńska, E.; Olszewski, T. K.; Górecki, M. RSC Adv. 2020, 10, 14618. 